\title{
THE ROLE OF VEGETATION IN SETTING STRONTIUM STABLE ISOTOPE RATIOS IN THE CRITICAL ZONE
}

\author{
JULIEN BOUCHEZ***, ${ }^{* *}$, and FRIEDHELM VON BLANCKENBURG**
}

\begin{abstract}
At Earth's surface the stable isotope ratio of strontium $\left({ }^{88} \mathrm{Sr} /{ }^{86} \mathrm{Sr}\right)$ is predominantly set by biological uptake of $\mathrm{Sr}$ and its storage in plant litter. This conclusion was reached from a stable isotope mass balance that was independently validated by direct determination of elemental fluxes between the Critical Zone compartments (rock, soil, vegetation, and stream water) of three field sites located in the Swiss Alps, the US Sierra Nevada, and the tropical highlands of Sri Lanka. These sites cover a gradient in erosion rates, which is inversely related to the residence time of solids in the Critical Zone thereby constituting an "erodosequence". For eroding landscapes, previous stable isotope models predicted that isotope ratios are set by the rate at which secondary solids form during the conversion of rock to regolith. Counter to this expectation we found that, after release from primary minerals, $\mathrm{Sr}$ is partitioned into one fraction taken up by plants and the remainder into dissolved $\mathrm{Sr}$ flux. The formation of secondary weathering products such as clays and oxides plays a subordinate role in determining the $\mathrm{Sr}$ budget. $\mathrm{A} \mathrm{Sr}$ isotope fractionation factor for biological uptake was determined for each of the three ecosystems from the average $\mathrm{Sr}$ stable isotope composition in bulk plants and its dissolved counterpart in stream water. This fractionation factors range from $c a .-0.3 \%$ for the Alps and Sierra Nevada to $\sim 0 \%$ for the tropical Sri Lanka site. That these isotope fingerprints caused by biologic uptake are preserved means that more $\mathrm{Sr}$ was physically removed in plant litter than recycled. Such Sr removal in plant litter appears to be strongest at the slowly-eroding site, whereas the dissolved $\mathrm{Sr}$ export by streams is highest at the site with the fastest erosion rate. There, all $\mathrm{Sr}$ taken up by plants is returned from litter back into solution. The site with short residence time of solids is the only one at which parent material and dissolved export differ in their $\mathrm{Sr}$ isotope composition. Our study shows that the behavior of $\mathrm{Sr}$ in the Critical Zone is in stark contrast to that of metals of which the isotope fractionation is not affected by biological uptake (for example lithium, mostly set by formation of secondary solids) or affected by both secondary solid formation and biological uptake (for example silicon). Strontium stable isotope signatures offer the new opportunity to quantify nutrient cycling in the Critical Zone as a function of environmental and ecological parameters.
\end{abstract}

Key words: strontium isotopes, metal stable isotopes, erodosequence, weathering, Critical Zone, soils, isotope fractionation factors, denudation

\section{INTRODUCTION}

Weathering is a key biogeochemical process converting rock into soil, releasing nutrients into soil- and river water, balancing the atmospheric $\mathrm{CO}_{2}$ budget, and in general shaping Earth's surface. All these processes operate within the thin layer encompassing weathered rock, saprolite, soil, water, and biota now termed the Critical Zone (for example Anderson and others, 2007). Exploring the extraordinary complexity, heterogeneity, and interdependence of processes in the Critical Zone requires novel tools that disclose the functioning of this biogeochemical reactor. In this regard, much hope rests on the isotope ratios of metal (for example $\mathrm{Li}, \mathrm{Mg}, \mathrm{Si}, \mathrm{K}$, $\mathrm{Ca}, \mathrm{Cr}, \mathrm{Fe}, \mathrm{Cu}, \mathrm{Zn}, \mathrm{Sr}, \mathrm{Mo}, \mathrm{Ba}$, or U) and metalloid (for example B, Si, or Ge)

* Université de Paris, Institut de physique du globe de Paris, CNRS, F-75005, Paris, France

** GFZ German Research Centre for Geosciences, Earth Surface Geochemistry, Telegrafenberg, 14473 Potsdam, Germany and Institute of Geological Sciences, Freie Universität Berlin, 12249 Berlin, Germany

${ }^{\dagger}$ Corresponding author: bouchez@ipgp.fr 
elements (Schmitt and others, 2012; Wiederhold, 2015; Sullivan and others, 2016). The basic principle is simple and common to all these elements: as chemical elements are partitioned between the compartments of the Critical Zone - such as primary minerals, secondary solid phases, water, gases, microbes, or higher organisms like animals and plants - their stable isotopes undergo a certain degree of fractionation, leading to the build-up of specific isotope fingerprints in each compartment. Metal stable isotope systems are particularly sensitive to the formation of secondary weathering products in soils and rivers, such as clays and oxides; and to uptake by plants and other living organisms (Bullen and Eisenhauer, 2009; von Blanckenburg and others, 2009). These isotopic fingerprints can be employed to quantify the partitioning of elements between compartments, provided that a framework exists for their interpretation.

The sensitivity by which these isotope ratios record Critical Zone processes and fluxes is a matter of active research. In particular mass balance and reactive transport models suggest that metal stable isotope ratios vary with the rate at which solids (for example, Bouchez and others, 2013) and fluids (for example, Wanner and others, 2017; Druhan and Winnick, 2019; Golla and others, 2021) travel through the Critical Zone. These predictions are now supported by a number of field observations (Dellinger and others, 2015, 2017; Wang and others, 2015; Frings and others, 2016; Li and others, 2019; Frings and others, 2021a, 2021b). In particular, a simple steady-state mass balance framework (Bouchez and others, 2013) shows that the signatures of metal stable isotopes in the Critical Zone depend on (1) the isotope ratios of the parent material undergoing weathering; (2) the isotope fractionation factors involved when an element moves from one compartment to another; (3) the relative element fluxes between these compartments.

Amongst these three factors, the rate at which solid material is advected towards the Earth surface by erosion and thus the chemical weathering rate and intensity (for example, Ferrier and Kirchner, 2008) has been shown to be the key determinant of isotope ratio differences between rock and fluid (for example, Dellinger and others, 2015). This rate is in turn driven by the erosion rate, the rate of removal of matter from the Earth surface. If we are to use metal stable isotopes in dissolved and particular river loads to characterize the functioning of the Critical Zone over large continental areas (for example, Dellinger and others, 2015), or if we are to reconstruct paleoenvironments from these isotopes extracted from sedimentary archives (for example, Misra and Froelich, 2012; Fontorbe and others, 2020), then constraining how the stable isotope signatures of these metals vary at Earth's surface as a function of the erosion rate is an essential prerequisite.

Biological cycling is a major factor in isotope partitioning at Earth's surface (for example, Schmitt and others, 2012). Consequently, metal isotope ratios in the Critical Zone are now used to constrain the fate of rock-derived nutrients after acquisition by plants (for example, Uhlig and others, 2017; Baronas and others, 2020; Oeser and von Blanckenburg, 2020a). A simple yet important consideration dictates that only if elemental recycling by plants is incomplete, meaning that a fraction of a bio-utilized element contained in particulate organic material or biosilica is exported by erosion, the control over the isotope fingerprints of rock-derived nutrients in Critical Zone compartments emerges (Bouchez and others, 2013; Uhlig and others, 2017; Oeser and von Blanckenburg, 2020a; Charbonnier and others, 2020; Frings et al., 2021a). If, in contrast, in a steady-state system a bio-utilized element is fully returned to soil by litterfall and is redissolved thereafter, stable isotope signatures of this element dissolved in soil or river water remain unaffected by plant uptake - regardless of the uptake flux.

However, many stable isotope systems are sensitive to both biological cycling and formation of secondary weathering products and (for example, $\mathrm{Si}$ and $\mathrm{Ge} / \mathrm{Si}$ : Baronas and others, 2018; Frings and others, 2021a, 2021b; Ba: Charbonnier and others, 2020; 
Mg: Schuessler et al., 2018), preventing the simple derivation of relative fluxes into either of these compartments.

In this regard, the stable isotopes of the trace alkali earth element strontium $(\mathrm{Sr})$ offer the opportunity to single out biological processes in the Critical Zone. Although $\mathrm{Sr}$ is not an essential nutrient per se, it is utilized by higher plants (for example, Bullen and Chadwick, 2016). A simple explanation for this observation is the biogeochemical similarity between Sr and the macro-nutrient calcium (Ca; Rediske and Selders, 1953; Gupta and others, 2018; Burger and Lichtscheidl, 2019). Also, strontium is one of the most soluble elements: a behaviour that is consistent with the low affinity of Sr for secondary phases (with the exception of soils developed on volcanic substrates where smectite can incorporate Ca and most likely Sr; Dahlgren and others, 2004; or in soils where pedogenic carbonates form; Quade and others, 1995). We know this from the comparison of its abundance as a dissolved species in world rivers with its concentration in rocks relative to other elements (Gaillardet and others, 2014).

Strontium has four naturally-occurring isotopes, all of which are stable: ${ }^{84} \mathrm{Sr}$ (natural abundance: $0.56 \%),{ }^{86} \mathrm{Sr}(9.86 \%)$ and ${ }^{88} \mathrm{Sr}(82.58 \%)$. The radiogenic isotope ${ }^{87} \mathrm{Sr}(c a .7 \%)$ varies in its abundance relative to the other isotopes due to the $\beta^{-}$radioactive decay of ${ }^{87} \mathrm{Rb}$ (half-life of $49 \mathrm{Gyr}$; Faure and Powell, 1972). The ${ }^{87} \mathrm{Sr} /{ }^{86} \mathrm{Sr}$ system constitutes the well-known Rb-Sr geochronometer and serves to trace the provenance of $\mathrm{Sr}$ at the Earth surface as a function of age and $\mathrm{Rb} / \mathrm{Sr}$ ratio of source rocks. Importantly, while shifts in the isotope ratios of all $\mathrm{Sr}$ isotopes are controlled by massdependent fractionation, such shift in the "radiogenic" ${ }^{87} \mathrm{Sr} /{ }^{86} \mathrm{Sr}$ ratio is removed by normalization during reduction of mass-spectrometric data. Therefore, the Sr isotope system is of particular interest for Earth surface studies as it features both the radiogenic ${ }^{87} \mathrm{Sr} /{ }^{86} \mathrm{Sr}$ ratio providing information about element sources, and the stable ${ }^{88} \mathrm{Sr} /{ }^{86} \mathrm{Sr}$ ratio that shifts with isotope fractionation, thereby yielding insight into transformations in the binding form of Sr.

The Sr radiogenic isotope system has long been used for the study of the Critical Zone to quantify the differential weathering rates of silicate minerals in natural settings (for example, Bain and Bacon, 1994; Blum and Erel, 1997; Bullen and others, 1997; Clow and others, 1997; Nezat and others, 2010); or to identify the sources of nutrients for plants and their shift during soil development and ecosystem history (for example, Åberg and others, 1990; Kennedy and others, 1998; Vitousek and others, 1999; Poszwa and others, 2002; Bullen and Bailey, 2005; Pett-Ridge and others, 2009; Oeser and von Blanckenburg, 2020b). By comparison, studies of Sr stable isotope ratios in weathering systems are still scarce. The range of variation in the ${ }^{88} \mathrm{Sr} /{ }^{86} \mathrm{Sr}$ ratio is only slightly above one permil in planetary materials (Charlier and others, 2012; Moynier and others, 2012). This range is much more limited in terrestrial rocks (Amsellem and others, 2018). A number of field-, experimental-, and theoretical studies have demonstrated the preferential incorporation of ${ }^{86} \mathrm{Sr}$ into abiotic and biogenic carbonates and sulfates (Rüggeberg and others, 2008; Ohno and others, 2008; Böhm and others, 2012; Raddatz and others, 2013; Stevenson and others, 2014; Widanamage and others, 2014, 2015; Al-Khatib and others, 2016). However, to date only preciously few studies have shown fractionation of Sr isotopes during Critical Zone processes, namely the formation of soil secondary carbonates (Shalev and others, 2013, 2017) and plant uptake (de Souza and others, 2010; Bullen and Chadwick, 2016; Guilbourdenche and others, 2020; Oeser and von Blanckenburg, 2020a). Indirect evidence from a series of larger-scale studies suggests that plant uptake (Andrews and others, 2016), secondary phase formation (Wei and others, 2013; Chao and others, 2015; Pearce and others, 2015a; Stevenson and others, 2016; Stevenson and others, 2018), anthropogenic inputs (Pearce and others, 2015b), or differential weathering 
of minerals (Andrews and Jacobson, 2017, 2018) might all affect the isotope composition of dissolved Sr exported from watersheds.

In this study, we explore how stable $\mathrm{Sr}$ isotope ratios vary with the rate of matter removal at the Earth surface, using field sites for which the erosion rate is well characterised. These sites constitute a gradient of erosion rates, a so-called "erodosequence", resulting in a gradient of residence time of solids in the Critical Zone, from long (Sri Lankan Highlands) through intermediate (Sierra Nevada) to short residence times (Swiss Alps). These three sites are well characterized for total mass and element-specific rate and fluxes of weathering and erosion (see the companion paper by von Blanckenburg and others, 2021). Our objectives are to (1) determine the partitioning of fluxes between compartments by means of a stable isotope-based mass balance, and we ground-truth these novel approaches with specific, element-based mass balances; (2) use the estimates from both these approaches to interrogate whether indeed biological cycling rather than partitioning into abiogenic solids plays the predominant role in the cycle of $\mathrm{Sr}$ and its isotope partitioning; (3) use the measured isotope differences to estimate Sr stable isotope fractionation factors; (4) determine the dominant processes that set Sr fluxes in the Critical Zone. Finally, we provide recommendations on the use of $\mathrm{Sr}$ stable isotopes to characterize catchment-scale ecosystem nutrition strategies from river data.

\section{STUDY SITES, SAMPLES, AND ANALYTICAL METHODS}

The three sites (fig. 1) define a gradient in weathering regime, from slow landscape-scale denudation, erosion, and weathering rates associated with thick regolith and high weathering intensity (Sri Lanka), to fast denudation, erosion, and weathering rates associated with thin regolith and low weathering intensity (Swiss Alps). We describe these sites briefly; for a more detailed description the reader is referred to von Blanckenburg and others (2021), who report also elemental compositions and fluxes for each site.

In the Swiss Alps our main sampling site (called the "Goms" site) is located on a soil-mantled ridge on top of a south-facing slope of the Upper Rhone valley, and is covered by grass (fig. 1). The main rock type is foliated gneiss with quartz, plagioclase, and orthoclase as major minerals, and biotite and muscovite as minor minerals. Soil of $30 \mathrm{~cm}$ thickness is underlain by thin saprolite. The average soil denudation rate is $38.4 \mathrm{~mm} \mathrm{ky}^{-1}\left(103 \pm 40 \mathrm{t} \mathrm{km}^{-2} \mathrm{y}^{-1}\right.$; note that the landscape-scale denudation rate measured from cosmogenic nuclides in river sediments reach 220 to $5,500 \mathrm{t} \mathrm{km}^{-2} \mathrm{y}^{-1}$; Norton and others, 2010). Norton and von Blanckenburg (2010) determined a mean Chemical Depletion Fraction (CDF, that is the relative amount of initial mass rock lost to solution through weathering; see equation (4) of von Blanckenburg and others, 2021) of 0.30 , yielding a chemical weathering rate of $12 \mathrm{~mm} \mathrm{ky}^{-1}\left(32 \mathrm{t} \mathrm{km}^{-2} \mathrm{y}^{-1}\right)$ and an erosion rate of $26 \mathrm{~mm} \mathrm{ky}^{-1}\left(71 \mathrm{t} \mathrm{km}^{-2} \mathrm{y}^{-1}\right)$. Using a regolith depth of $0.35 \mathrm{~m}$ and this denudation rate, a regolith residence time of $10 \mathrm{kyr}$ can be calculated for this site (von Blanckenburg and others, 2021). The mean annual temperature and precipitation are $3.1^{\circ} \mathrm{C}$ and $1,137 \mathrm{~mm}$, respectively, and the Gross Primary Production (GPP) is estimated at $779 \pm 18 \mathrm{t} \mathrm{km}^{-2} \mathrm{y}^{-1}$ (von Blanckenburg and others, 2021). A second site ("Aare" site) is located in the Rhine valley a few $\mathrm{km}$ beneath the Grimsel Pass in the upper Aare valley. At this site the Aare granitic parent rock (with similar albeit slightly more felsic mineralogy compared to the Goms parent rock) crops out as a flat, glacially eroded surface. The granitic rock is overlain by a $c a .10 \mathrm{~cm}$-thick organic-rich "mat" rather than by a structured regolith. However, isolated mineral grains can be found within the mat, the vegetation atop consisting mostly of grass and shrubs. We also collected several groundwater samples in a tunnel located $400 \mathrm{~m}$ below the surface close to Grimsel Pass, part of an experimental study site on the geological 

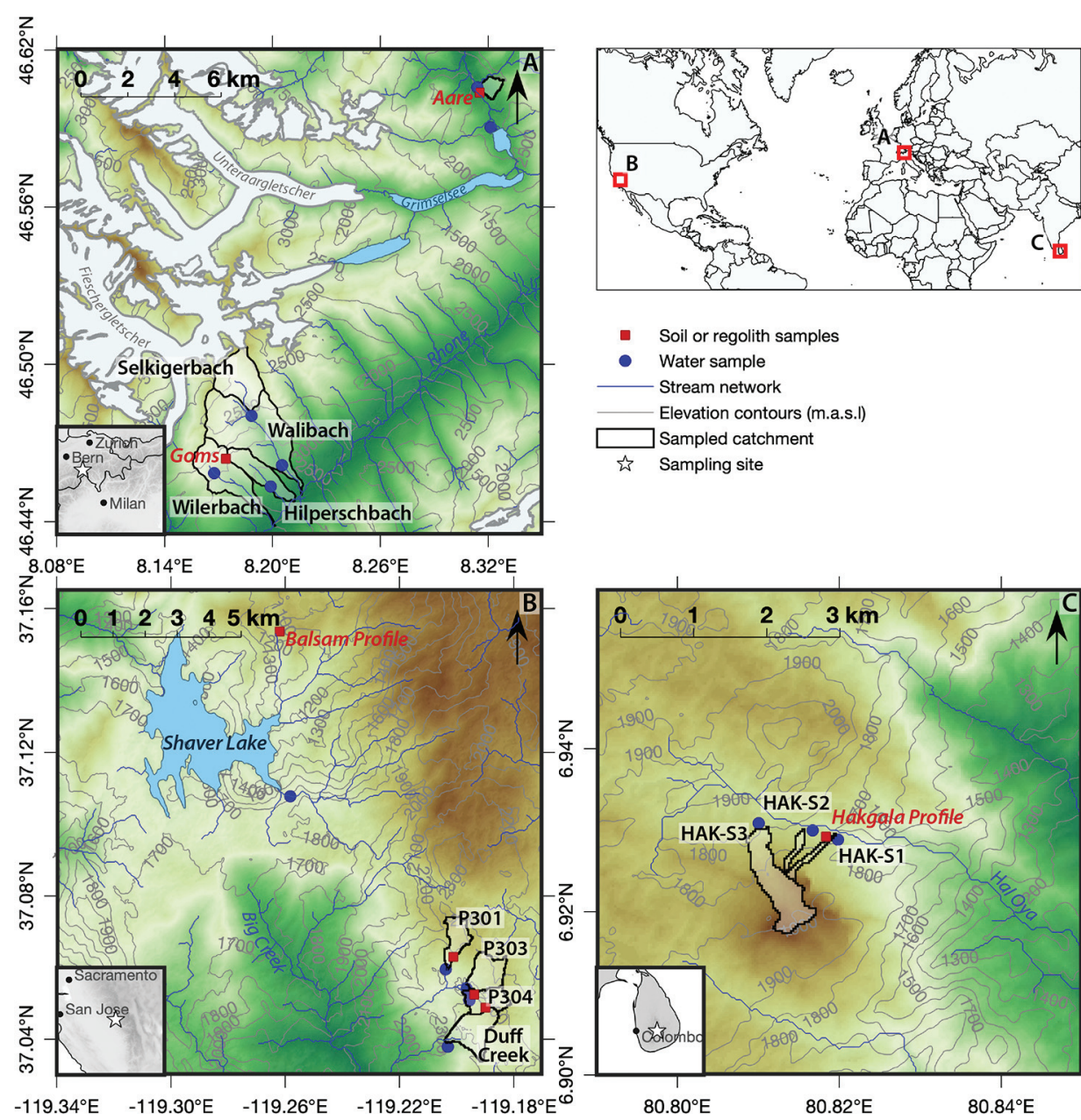

- Soil or regolith samples

- Water sample Stream network

Elevation contours (m.a.s.l)

Sampled catchment

is Sampling site

Fig. 1. Map of the sampling sites and sampling locations: Alps (A); Sierra Nevada (B); and Sri Lanka (C). In each of the three panels, the inset shows the location of the site within the region.

disposal of radioactive waste ("Grimsel Test Site"; Blechschmidt and Vomvoris, 2015), operated by the Swiss National Cooperative for the Disposal of Radioactive Waste. Rock, soil, soil water, stream water (including the large Upper Rhone River), ground water, stream bed sediments, and plant samples from the Alps sites were taken during a field campaign in July 2010.

The Sierra Nevada sampling site is located in and around the Kings River Experimental Watershed (KREW) in the Southern Sierras mountain range, USA (fig. $1)$. We sampled the compartments of the weathering zone in particular within the Southern Sierras Critical Zone Observatory (CZO) located within four small forested catchments (drainage area $<1 \mathrm{~km}^{2}$ ) located at an elevation ranging from 1,479 to 2,113 m. At these sites the bedrock is dominated by the "Dinky Creek" granodiorite. The annual precipitation is 750 to $2,000 \mathrm{~mm}$ and the mean annual air temperature is $7.8^{\circ} \mathrm{C}$ (Liu and others, 2013). Dixon and others (2009) report average denudation rates of $82 \mathrm{~mm} \mathrm{ky}^{-1}\left(221 \mathrm{t} \mathrm{km}^{-2} \mathrm{y}^{-1}\right)$ and a CDF of 0.36 . This results in a chemical weathering rate of $30 \mathrm{~mm} \mathrm{ky}^{-1}\left(80 \mathrm{t} \mathrm{km}^{-2} \mathrm{y}^{-1}\right)$ and an erosion rate of $52 \mathrm{~mm} \mathrm{ky}{ }^{-1}$ 
$\left(141 \mathrm{t} \mathrm{km}^{-2} \mathrm{y}^{-1}\right)$. Using a regolith depth of $\sim 7 \mathrm{~m}$ (as measured for the "Balsam profile", see below) and the above denudation rates, a regolith residence time of $86 \mathrm{ky}$ is calculated. The GPP is estimated to be $1348 \pm 54 \mathrm{t} \mathrm{km}^{-2} \mathrm{y}^{-1}$ (von Blanckenburg and others, 2021). Most samples were collected during a field campaign in May 2010 (Uhlig and others, 2017). Several Critical Zone compartments (including upper saprolite, soil, soil water, stream water, bed sediments, and plants) were sampled in the catchments. In addition, a whole regolith profile (here called the "Balsam profile") was sampled along a road cut from the top soil to bedrock. This sample set is complemented by stream water collected at five locations in February 2011, February 2012, and June 2012, and by stream and ground water samples taken in December 2009.

The third sampling site is located in the Central Highlands of Sri Lanka (fig. 1). The Hagkala sampling site is underlain by charnockite, a high-grade metamorphic rock that makes up approximately $50 \%$ of the bedrock of the Highlands. Most of the landscape is mantled by a thick regolith cover (several meters) and by a high-canopy $(20 \mathrm{~m})$ tropical forest. The topography is relatively steep, but erosion and weathering rates are low (Hewawasam and others, 2003, 2013; von Blanckenburg and others, 2004; Behrens and others, 2015). The regolith sampling site, located at an altitude of $1,753 \mathrm{~m}$, is characterized by a mean annual temperature of $16^{\circ} \mathrm{C}$ and a mean annual precipitation of $2,013 \mathrm{~mm}$. The thick regolith profile $(\sim 10 \mathrm{~m})$ has been shown to be affected in its uppermost meter by the input of carbonate-rich dust, either from local or global origin (Hewawasam and others, 2013). The average denudation rate on soils in the vicinity of the sampled profile is $15.5 \mathrm{~mm} \mathrm{ky}^{-1}$ (or $42 \mathrm{t} \mathrm{km}^{-2} \mathrm{y}^{-1}$; Hewawasam and others, 2003, 2013). The CDF is around 0.5 at the top of the saprolite, thus yielding similar values for erosion and weathering rates around $7 \mathrm{~mm} \mathrm{~mm} \mathrm{ky}{ }^{-1}\left(21 \mathrm{t} \mathrm{km}^{-2}\right.$ $\mathrm{y}^{-1}$ ). Using a regolith depth of $10 \mathrm{~m}$ and the above denudation rates, a regolith residence time of $600 \mathrm{ky}$ results (von Blanckenburg and others, 2021). The GPP at this site is $2957 \pm 106 \mathrm{t} \mathrm{km}^{-2} \mathrm{y}^{-1}$. Rock, saprolite, soil, soil water, and plant samples were all taken during a field campaign carried out in October 2010 (Hewawasam and others, 2013). Water was sampled in three small creeks draining pristine hillslopes and located within a few hundreds of meters from the Hagkala regolith profile, and in the larger Uma Oya River that drains both pristine forests and areas affected by agricultural activity in October 2010, January 2012, and April 2012 (Hewawasam and others, 2013).

Sr isotope ratios were measured on a selection of rock, saprolite, soil, soil water, ground water, river water, and plant (both woody and leafy parts) samples from the three sites. For selected soil and saprolite samples, Sr isotope ratios were measured on sequential extractions (Appendix A) in addition to bulk analyses. All chemical procedures and measurements were performed at the HELGES laboratory of GFZ Potsdam (von Blanckenburg and others, 2016). Previous publications describe the methods used for mineralogical and elemental analyses (von Blanckenburg and others, 2021), sample digestion (Hewawasam and others, 2013; Uhlig and others, 2017; Schuessler and others, 2018; von Blanckenburg and others, 2021), as well as Sr chromatographic extraction and radiogenic isotope analysis (Hewawasam and others, 2013; Oeser and von Blanckenburg, 2020b; von Blanckenburg and others, 2021). Further details are provided here on sequential extractions of specific regolith fractions (Appendix A) and stable $\mathrm{Sr}$ isotope analysis (Appendix B). We report the Sr stable isotope composition as $\delta^{88} \mathrm{Sr}$, which is the deviation in permil of the ${ }^{88} \mathrm{Sr} /{ }^{86} \mathrm{Sr}$ ratio of the sample compared to that of the international isotope standard NIST SRM987. The uncertainty on sample ${ }^{87} \mathrm{Sr} /{ }^{86} \mathrm{Sr}$ ratios and $\delta^{88} \mathrm{Sr}$ values are reported as $95 \%$ confidence intervals (C.I.) and are on the order of $10^{-5}$ and $0.03 \%$, respectively (Appendix B; tables A1 to SL3). All isotopic and elemental concentration data produced in this study are provided in an open-access online publication (Bouchez and von Blanckenburg, 2021) 
hosted at GFZ data services. Hereafter these tables are called "Data Tables" (http:/ / earth.eps.yale.edu/\%7eajs/SupplementaryData/2021/Bouchez). All samples have been attributed a unique identifier, an "International Geo Sample Number" (IGSN).

\section{RESULTS}

We focus here on the results pertaining to Sr elemental and isotope behaviour at the three sites, and we refer the reader to the companion paper by von Blanckenburg and others (2021) on these field settings for more detailed information on chemical weathering intensity and erosion and weathering fluxes.

\section{Sr Abundance}

The loss of Sr relative to parent material during weathering can be quantified using $\tau_{\mathrm{Sr}}$, the "mass transfer coefficient" of Sr (eq 5 of von Blanckenburg and others, 2021). In the Swiss Alps $\tau_{\mathrm{Sr}}$ range from -0.23 (meaning that $23 \%$ of the Sr initially present in the bedrock was lost to solution during weathering) in the lowermost horizons to -0.65 in the $\mathrm{O}$ horizon (Data Table A1; fig. 2). Values of $\tau_{\mathrm{Sr}}$ at the Aare site reach around -0.9 , indicating strong $\mathrm{Sr}$ depletion there (Data Table A1). In Sierra Nevada $\mathrm{Sr}$ is only moderately lost at the bottom of the Balsam profile $\left(\tau_{\mathrm{Sr}}=-0.57\right)$, but loss increases at the top of the profile $\left(\tau_{\mathrm{Sr}}=-0.78\right.$; Data Table SN1; fig. 2). Sr loss is weaker in the augered saprolite from the Providence Creek catchment $\left(\tau_{\mathrm{Sr}}=-0.53\right.$ to -0.62$)$, and even less so in cored top soil samples $\left(\tau_{\mathrm{Sr}}=-0.24\right.$ to -0.49$)$. In Sri Lanka, samples from different layers of a "corestone" collected in the deep saprolite display $\tau_{\mathrm{Sr}}$ between -0.17 and 0.18 , indicating no significant bulk loss of Sr beyond uncertainty at this early stage of weathering (Data Table SL1; fig. 2 ). However, $\tau_{\mathrm{Sr}}$ indicate rapid and strong loss of $\mathrm{Sr}$ in the saprolite, with values ranging from -0.32 in the lower saprolite to -0.99 in the upper part of the saprolite. Values of $\tau_{\mathrm{Sr}}$ are consistently higher in the top soil ( -0.94 to -0.96 ; Data Table SL1; fig. 2), which can be explained by Sr addition through dust (Hewawasam and others, 2013).

Results from sequential extractions (Appendix A) disclose the amounts of $\mathrm{Sr}$ stored in the secondary chemical compartments of the regolith. Water-extractable $\mathrm{Sr}$ typically corresponds to less than $1 \%$ of bulk $\mathrm{Sr}_{\text {. }} \mathrm{NH}_{4} \mathrm{Ac}$-extractable $\mathrm{Sr}$ is generally also lower than $1 \%$ of bulk Sr, but can attain $8.5 \%$ in top soil samples of Sri Lanka (Data Table E). Carbonate-bound Sr has been quantified in only two samples from Sierra Nevada and Sri Lanka, respectively, and is around 1\% of bulk Sr. Strontium associated with (hydr) oxides extracted using $\mathrm{NH}_{2} \mathrm{OH}$ represents between 0.5 and $2.4 \%$ of bulk Sr. Clay-sized fraction Sr ranges from less than $1 \%$ to more than $10 \%$ in rindlet samples from the corestone of the Sri Lankan regolith profile.

In the Swiss Alps, stream water dissolved Sr concentration ranges from 1.5 to 106 $\mu \mathrm{g} \mathrm{L}^{-1}$ in the Goms (von Blanckenburg and others, 2021; Data Table A2). This large variation exceeds the variation in dissolved $\mathrm{Na}$, a conservative element, and is thus not exclusively due to a dilution effect. Dissolved $\mathrm{Sr}$ concentrations and $\mathrm{Sr} / \mathrm{Na}$ ratios are systematically higher in groundwater samples collected in the tunnel of the Grimsel Test Site, where dissolved Sr concentrations range from 152 to $557 \mu \mathrm{g} \mathrm{L}^{-1}$. In soil water samples of the Sierra Nevada site, Sr concentrations range from 21 to $106 \mu \mathrm{g} \mathrm{L}^{-1}$, which is in the same range as river and ground water samples that range from 15 to $119 \mu \mathrm{g} \mathrm{L}^{-1}$ (Data Table SN2). At the Sierra Nevada site the highest $\mathrm{Sr} / \mathrm{Na}$ ratios are observed for soil water samples (4.6-122 mmol mol${ }^{-1}$ ) and the lowest $\mathrm{Sr} / \mathrm{Na}$ ratios for ground water samples $\left(0.28-4.5 \mathrm{mmol} \mathrm{mol}^{-1}\right)$. In Sri Lanka, the dissolved Sr concentrations range from 2.9 to $27 \mu \mathrm{g} \mathrm{L}^{-1}$ in soil solutions sampled in October 2010 with tension lysimeters, and from 2.0 to $116 \mu \mathrm{g} \mathrm{L}^{-1}$ in stream water (Data Table SL2). This variability is strongly reduced by Na normalisation, hinting at a strong dilution effect. 

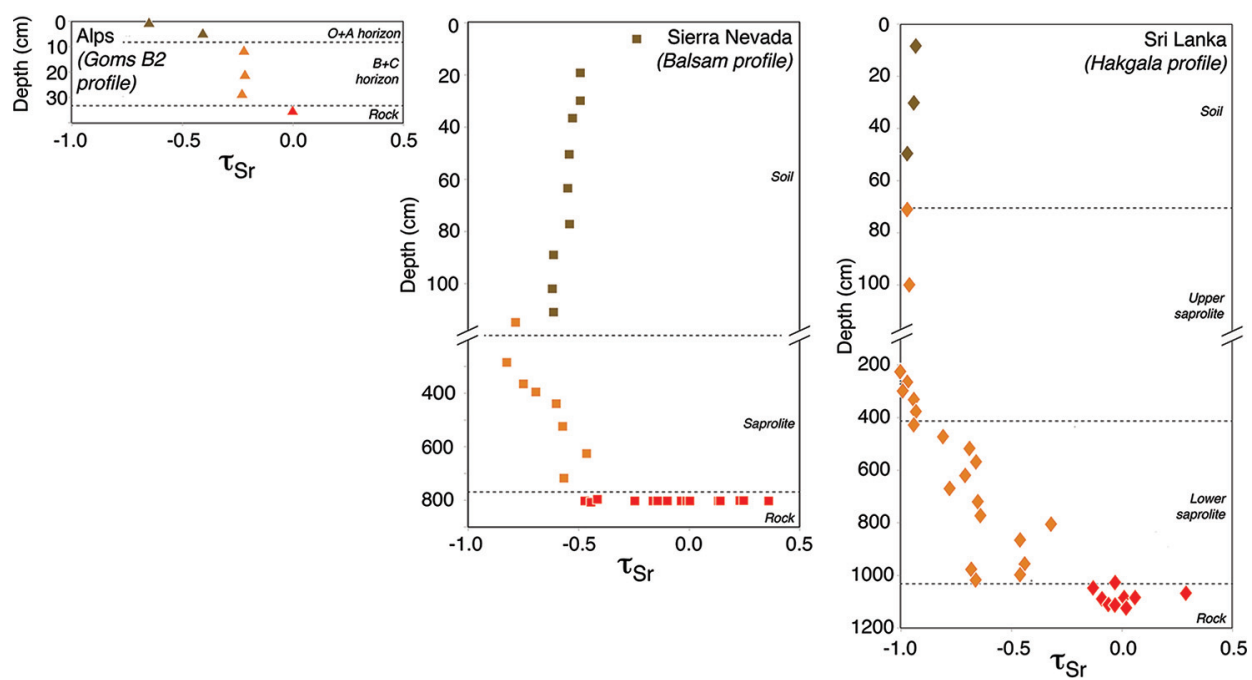

Fig. 2. Sr mass transfer coefficient $\left(\tau_{\mathrm{Sr}}\right)$ as a function of depth in the regolith profiles of the three sites of the erodosequence.

In vegetation samples, Sr concentrations are significantly lower in plant material from the Swiss Alps than those from others sites, ranging between 2.2 and $10.7 \mu \mathrm{g} \mathrm{g}^{-1}$ (von Blanckenburg and others, 2021; Data Table A3). Higher Sr concentrations were measured in plant samples from Sierra Nevada, with concentrations ranging from 4.6 to $63.7 \mu \mathrm{g} \mathrm{g}^{-1}$ (Data Table SN3). Lower Sr concentrations are observed in woody organs than in foliage. In Sri Lanka, the concentration of $\mathrm{Sr}$ in plant samples ranges from $2.0 \mu \mathrm{g} \mathrm{g}^{-1}$ to $59.0 \mu \mathrm{g} \mathrm{g}^{-1}$ (Data Table SL3). For a given species, woody organs (branches and twigs) have lower concentrations than foliage, by a factor of 2 to 3 .

Ratios of $\mathrm{Sr}$ to $\mathrm{Ca}$ are broadly similar between the exchangeable extracts from the regolith and the plant samples. Nevertheless, and as observed by previous studies (Dasch and others, 2006; Oeser and von Blanckenburg, 2020b) discrimination of Sr relative to Ca during plant uptake is apparent along the erodosequence from the comparison of $\mathrm{Sr} / \mathrm{Ca}$ ratios between the exchangeable pool and the plant parts. $\mathrm{Sr} /$ Ca ratios range from 7 to $35 \mathrm{mmol} \mathrm{mol}^{-1}$ in the exchangeable pool (with overall higher ratios in deep saprolite samples than in topsoil samples, and with higher ratios in the $\mathrm{NH}_{4} \mathrm{Ac}$-extractable pool than in the $\mathrm{H}_{2} \mathrm{O}$-extractable pool; Data Table E) whereas $\mathrm{Sr} / \mathrm{Ca}$ ratios are 0.05 to $13 \mathrm{mmol} \mathrm{mol}^{-1}$ in plants (Data Tables A3, SN3, SL3). In addition, $\mathrm{Sr} / \mathrm{Ca}$ ratios are usually higher in woody parts than in foliage by a factor of $\sim 2$ (Data Tables A3, SN3, SL3), showing the enrichment of Ca over Sr from wood to foliage in plants (Poszwa and others, 2000; Drouet and others, 2007; de Souza and others, 2010).

\section{Sr Radiogenic Isotope Ratios}

The ${ }^{87} \mathrm{Sr} /{ }^{87} \mathrm{Sr}$ ratios and $\delta^{88} \mathrm{Sr}$ values are plotted in figures 3 and 4 . The three sites are distinct in their bedrock ${ }^{87} \mathrm{Sr} /{ }^{87} \mathrm{Sr}$ ratios (fig. 3), in line with the underlying lithology. In the Swiss Alps, saprolite samples have the least radiogenic ${ }^{87} \mathrm{Sr} /{ }^{86} \mathrm{Sr}$ ratios (around 0.7078) and are rather homogeneous with depth (Data Table A1; fig. 3). The stream water samples display large spatial variability (Data Table A2). Sr in the ground water samples collected deep in the Aare massif is more radiogenic than $\mathrm{Sr}$ in the majority of the other samples from the Swiss Alps, with ${ }^{87} \mathrm{Sr} /{ }^{86} \mathrm{Sr}$ ranging from 0.7176 to 
0.7235 . The grass sample from the Goms site is the least radiogenic of all vegetation samples from the Swiss Alps $\left({ }^{87} \mathrm{Sr} /{ }^{86} \mathrm{Sr}=0.7093\right.$, close to the value of the O horizon of the Goms regolith profile; Data Table A3). Higher ratios are observed for the vegetation samples from the Aare site $\left({ }^{87} \mathrm{Sr} /{ }^{86} \mathrm{Sr}=0.7119-0.7131\right)$, overlapping with the range defined by the soil water and soil samples from this site.

In the Sierra Nevada the most radiogenic ${ }^{87} \mathrm{Sr} /{ }^{86} \mathrm{Sr}$ ratio of of 0.70993 is obtained for the Balsam rock sample (Data Table SN1; fig. 3). Saprolite samples are the least radiogenic of our entire sample set (fig. 3) and display the narrowest range at the scale of a site, with ${ }^{87} \mathrm{Sr} /{ }^{86} \mathrm{Sr}$ ratios ranging from 0.7078 to 0.7085 in (Data Table $\mathrm{SN1}$ ), from 0.7076 to 0.7089 in water samples (Data Table SN2), and from 0.7076 to 0.7082 in vegetation samples (Data Table SN3). No systematic trend in ${ }^{87} \mathrm{Sr} /{ }^{86} \mathrm{Sr}$ with depth is observed across the regolith (fig. 3) ${ }^{87} \mathrm{Sr} /{ }^{86} \mathrm{Sr}$ ratios in most streams are invariant within uncertainty (Data Table SN2). The ${ }^{87} \mathrm{Sr} /{ }^{86} \mathrm{Sr}$ ratios of the corresponding soil water samples (sampled within each stream's catchment) do not overlap with the range defined by the stream ratios, with no systematic mismatch, neither in terms of magnitude nor direction. ${ }^{87} \mathrm{Sr} /{ }^{86} \mathrm{Sr}$ ratios in seep and well water samples are in the same range as those of soil and stream water samples. Vegetation samples show ${ }^{87} \mathrm{Sr} /{ }^{86} \mathrm{Sr}$ ratios in the same range as saprolite and soil water samples (Data Table SN3; fig. 3). With the notable exception of the Pinus Ponderosa samples, woody and leafy parts of the plant samples yield the same ${ }^{87} \mathrm{Sr} /{ }^{86} \mathrm{Sr}$ ratios, but these ratios show significant variability from one specimen to the other (or from one species to the other). The tall coniferous samples (Pinus Ponderosa and Pinus Jeffreyi) display more radiogenic ratios $\left({ }^{87} \mathrm{Sr} /{ }^{87} \mathrm{Sr}=0.7080-\right.$ 0.7082) than those of bush samples (Ceanothus cordulatus and Arctostaphylos Manzanita; 0.7076-0.7077; Data Table SN3).

The most radiogenic ${ }^{87} \mathrm{Sr} /{ }^{87} \mathrm{Sr}$ ratios are observed for Sri Lanka and range from 0.7181 to 0.8131 for regolith samples (Data Table SL1), 0.7177 to 0.7239 for water samples (Data Table SL2), and 0.7119 to 0.7186 for plant samples (Data Table SL3). For the saprolite and corestone samples, the ${ }^{87} \mathrm{Sr} /{ }^{86} \mathrm{Sr}$ ratios of the "exchangeable" and "oxihydroxide" fractions are usually more radiogenic than the corresponding bulk samples (Data Table SL1). However, the clay-sized fractions display higher ${ }^{87} \mathrm{Sr} /{ }^{87} \mathrm{Sr}$ ratios only in the saprolite, whereas these ratios are in remarkable agreement with those of the bulk sample for the corestone. Less radiogenic ratios in top soil samples and soil and river water indicate dust inputs, as shown by Hewawasam and others (2013) and Schuessler et al. (2018). This less radiogenic, atmospherederived Sr component is also present in the vegetation samples (Data Table SL3; fig. 3). Significant temporal variability in the ${ }^{87} \mathrm{Sr} /{ }^{87} \mathrm{Sr}$ ratio is observed for the stream water samples, especially for the large Uma Oya (with ${ }^{87} \mathrm{Sr} /{ }^{87} \mathrm{Sr}$ varying from less than 0.718 to nearly 0.723 across the sampling period; Data Table SL2). Woody and leafy parts of any given tree agree in their ${ }^{87} \mathrm{Sr} /{ }^{87} \mathrm{Sr}$ ratios. At the three sites, the similarity in ${ }^{87} \mathrm{Sr} /{ }^{86} \mathrm{Sr}$ ratios between the plant sample parts and the top soil exchangeable pool is compatible with the exchangeable pool being the source of Sr to plants (as already shown by for example, Poszwa and others, 2002; Bullen and Chadwick, 2016; Oeser and von Blanckenburg, 2020a).

\section{Sr Stable Isotope Signatures}

Values of $\delta^{88} \mathrm{Sr}$ across our sample set range from $-0.28 \%$ to $0.57 \%$, which encompasses the entire range range reported to date for terrestrial samples with the exception of animal tissues (Hajj and others, 2017). The rock sample analyzed in the Swiss Alps (Goms site) displays a $\delta^{88} \mathrm{Sr}$ value of $0.23 \%$, slightly lower than the regolith samples from both the Goms and Aare sites (with ${ }^{88}$ Sr values of $0.27 \%$ and $0.34 \%$, respectively; Data Table A1; fig. 4). The $\mathrm{NH}_{4}$ Ac-extractable and clay-sized Sr pools of 

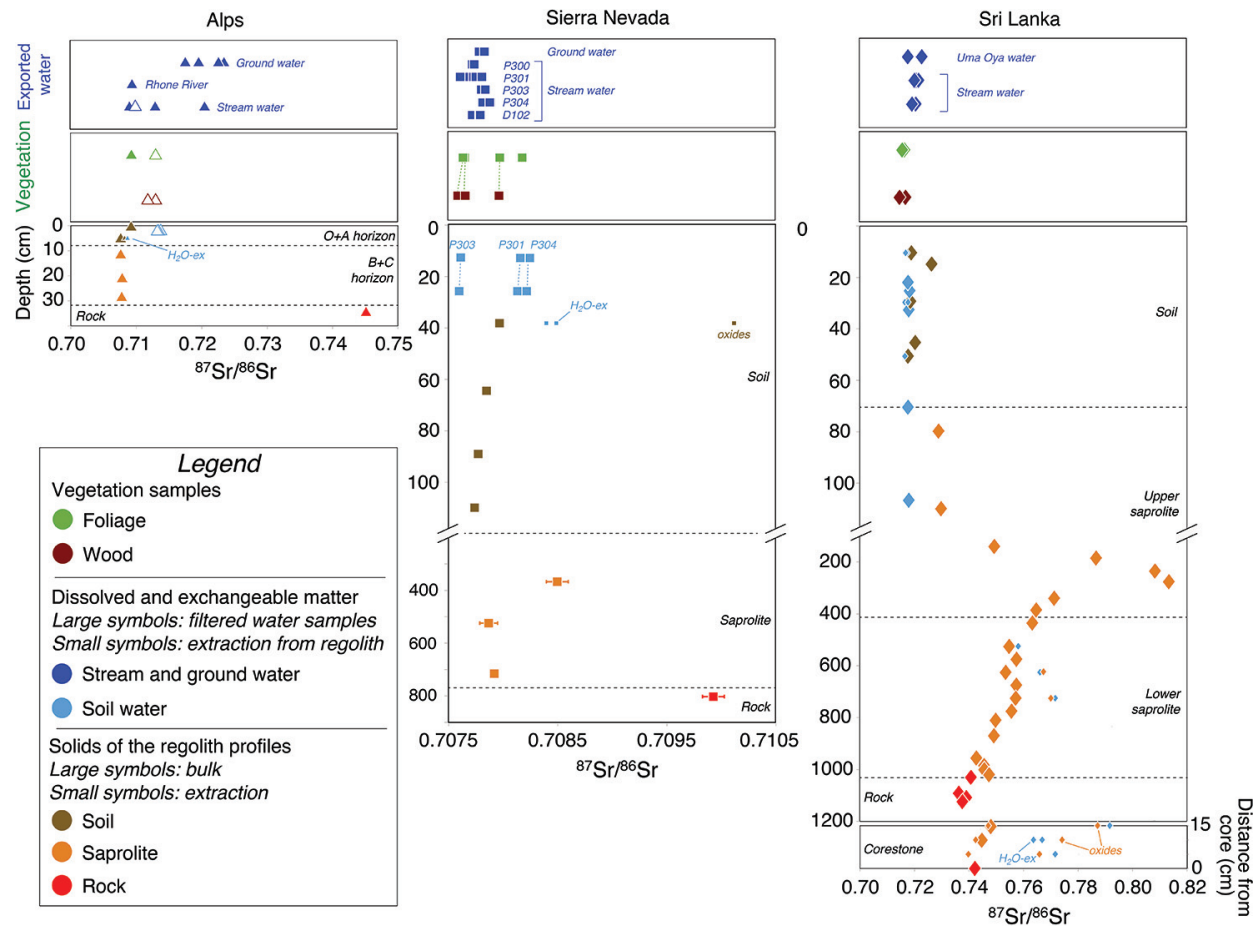

Fig. 3. ${ }^{87} \mathrm{Sr} /{ }^{86} \mathrm{Sr}$ "radiogenic" isotope ratios in the compartments of the Critical Zone at the three sites of the erodosequence. For soil and saprolite, large symbols represent bulk data and small symbols represent data from sequential extractions. If not labeled otherwise (" $\mathrm{H}_{2} \mathrm{O}$-ex"), small light blue symbols correspond to $\mathrm{NH}_{4} \mathrm{Ac}$ extracts. If not labeled otherwise ("oxides"), small orange symbols represent clay extracts. For the Alps, closed symbols represent samples from the Goms site, and open symbols samples from the Aare site.

the Goms A horizon have a similar $\delta^{88} \mathrm{Sr}$ value at $0.14 \%$ and $0.22 \%$, within the range defined by the regolith bulk samples (Data Table A1). The stream and ground water samples show a large range of $\delta^{88} \mathrm{Sr}$ values $(0.33 \%$ to $0.47 \%$ for stream water and $0.32 \%$ to $0.52 \%$ for ground water; Data Table A2), which is intermediate between the saprolite and soil water samples (fig. 3). The lowest $\delta^{88} \mathrm{Sr}$ values in the Alps are obtained for the plant samples $(0.03 \%$ to $0.23 \%$; Date Table A3).

The highest $\delta^{88} \mathrm{Sr}$ value of all rock samples is obtained for the Sierra Nevada rock (0.35 \%; Data Table SN1; fig. 4). Similar values are obtained across the Balsam regolith and augered bulk samples from the Providence Creek catchment (0.32 \%o to $0.40 \%$ ). Values of $\delta^{88} \mathrm{Sr}$ observed in sequential extractions also show a large range, but are mostly lower than the range defined by the bulk saprolite samples (Data Table $\mathrm{SN1}$; fig. 4). Soil water samples show lower values ( $-0.08 \%$ to $0.10 \%$; Data Table $\mathrm{SN2}$ ). By contrast, Sr in river and seep/well waters yield much higher $\delta^{88} \mathrm{Sr}$ values $(0.26 \%$ to $0.56 \%$ o $)$, overlapping with those of rock and saprolite samples. The range of $\delta^{88} \mathrm{Sr}$ values defined by the river water samples alone $(0.26 \%$ to $0.37 \%$ ) is fairly restricted, with no significant temporal variability. The range of $\delta^{88} \mathrm{Sr}$ values found in the vegetation is large $(-0.28 \%$ to $0.27 \%$; Data Table SL3; fig. 4). These values, close to those of soil water samples, are systematically smaller than those of the rock, saprolite, and stream and ground water samples.

In Sri Lanka, the analyzed rock samples show a significant variability in $\delta^{88} \mathrm{Sr}$ values, ranging from $0.07 \%$ to $0.26 \%$ (Data Table SL1). The range covered by the 

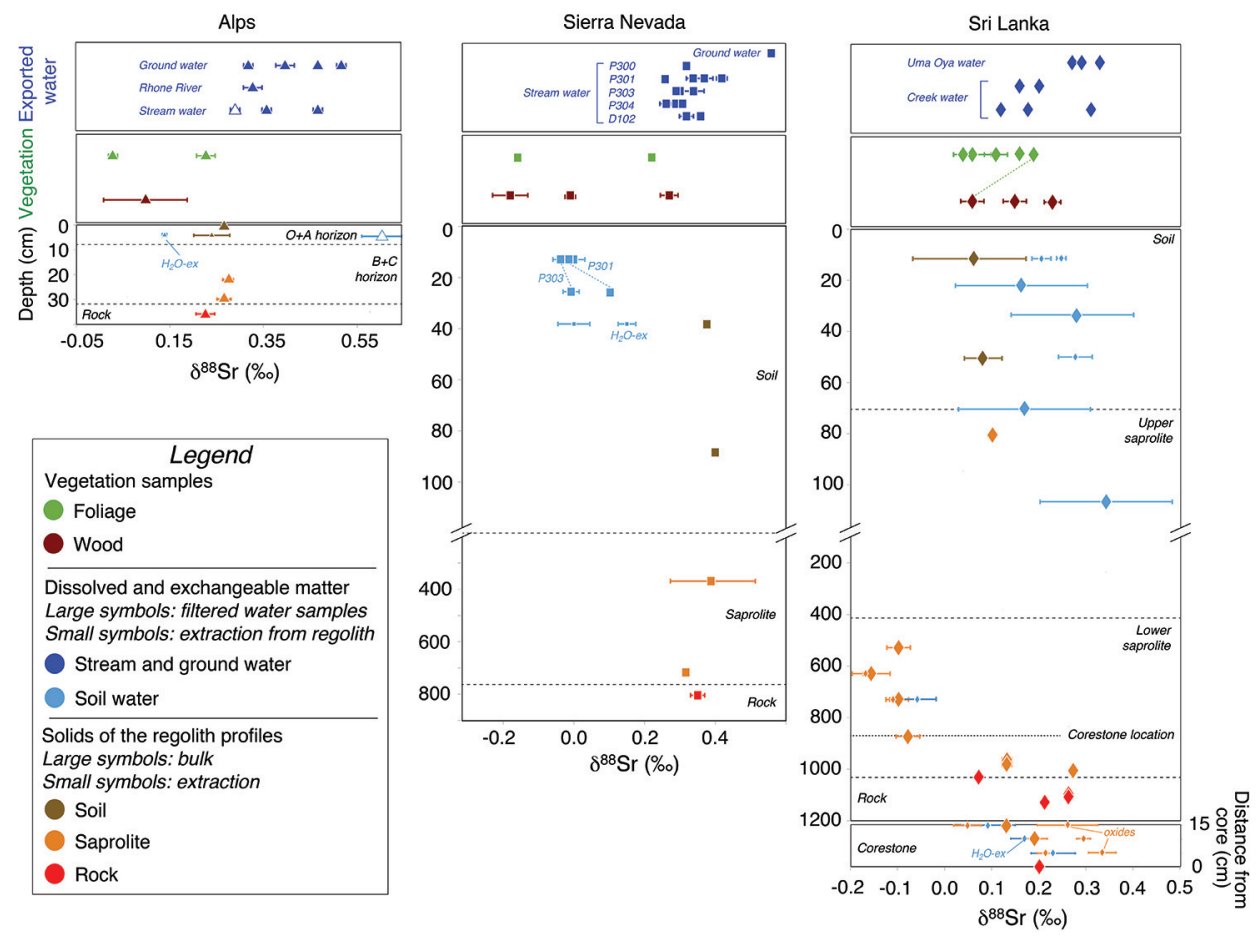

Fig. $4 .{ }^{88} \mathrm{Sr} /{ }^{86} \mathrm{Sr}$ "stable" isotope ratios $\left(\delta^{88} \mathrm{Sr}\right)$ in the compartments of the Critical Zone at the three sites of the erodosequence. For soil and saprolite, large symbols represent bulk data and small symbols represent data from sequential extractions. If not labeled otherwise (" $\mathrm{H}_{2} \mathrm{O}-\mathrm{ex}$ "), small light blue symbols correspond to $\mathrm{NH}_{4} \mathrm{Ac}$ extracts. If not labeled otherwise ("oxides"), small orange and brown symbols represent clay extracts. For the Alps, closed symbols represent samples from the Goms site, and open symbols samples from the Aare site.

corestone and lowermost saprolite samples is very similar $(0.13 \%$ to $0.27 \%$, but higher up in the saprolite, $\delta^{88} \mathrm{Sr}$ values are much lower (down to $-0.16 \%$ ). In the uppermost saprolite and in top soil, $\delta^{88} \mathrm{Sr}$ values increase back to $0.05 \%$ to $0.10 \%$ (Data Table SL1, fig. 4). Top soil water-extractable and $\mathrm{NH}_{4} \mathrm{Ac}$-extractable $\mathrm{Sr}$ yield $\delta^{88} \mathrm{Sr}$ values in the same range as soil water $(0.20 \%$ to $0.28 \%$, Data Table SL1), while clay-sized fractions from saprolite display much lower $\delta^{88} \mathrm{Sr}$ values $(-0.17 \%$ to $-0.11 \%$; Data Table SL1; fig. 4), similar to the bulk saprolite samples of the corresponding horizons. Sequential extractions of the corestone samples show substantial variability, even within a given pool. However, the range of $\delta^{88} \mathrm{Sr}$ values of extracted pools is overall lower than the corresponding bulk corestone samples (fig. 4). Soil water samples display $\delta^{88} \mathrm{Sr}$ values $(0.16 \%$ to $0.34 \%$ ) which is higher than those of the corresponding soil samples, and is overlapping with stream water samples $\left(0.12 \%\right.$ to $0.33 \%$; Data Table SL2; fig. 4). Dissolved $\delta^{88} \mathrm{Sr}$ varies neither with the depth of soil water nor with the period of stream water collected. The larger Uma Oya River yield $\delta^{88}$ Sr values in the upper range of those defined by the smaller creeks sampled in the vicinity of the Hagkala profile. The $\delta^{88} \mathrm{Sr}$ values of the vegetation samples $(0.03 \%$ to $0.23 \%$; Data Table SL3) are higher than those of the bulk soil samples but lower than those of the soil water. For the only specimen where the comparison can be made (Ixora walkeri), the leaves have a higher $\delta^{88} \mathrm{Sr}$ value than the corresponding woody part $(0.19 \%$ vs. $0.06 \%$ ). 


\section{DISCUSSION}

Stable isotope signatures in the Critical Zone are set by a combination of (1) the isotope ratio of the parent materials undergoing weathering; (2) the isotope fractionation factors of the processes biogeochemical transformations accompanying element fluxes between compartments; (3) the relative magnitude of these fluxes. In the Critical Zone the formation of secondary weathering products and biological uptake are thought to be decisive for controls (2) and (3). We first discuss Sr stable isotopes from our erodosequence within the context of these three controls, before exploring how Sr fluxes vary along the three sites.

\section{Strontium Isotope Composition of Parent Materials}

The stable isotope composition of the parent material undergoing weathering at the Earth surface sets a "baseline" for all isotope signatures that are observed in Critical Zone compartments, and thus needs to be determined for any cross-site study. Strontium ${ }^{88} \mathrm{Sr} /{ }^{86} \mathrm{Sr}$ ratios vary only marginally (typically by no more than $0.2-0.3 \%$ ) amongst different silicate minerals and rocks (Charlier and others, 2012; Moynier and others, 2012; Amsellem and others, 2018). Data collected on rocks along the erodosequence confirm this observation (fig. 4), with a rock $\delta^{88} \mathrm{Sr}$ value of $0.23 \%$ o $(\mathrm{n}=1)$ for the Alps (Data Table A1), $0.35 \%$ o $(\mathrm{n}=1)$ for Sierra Nevada (Data Table SN1), and $0.24 \pm 0.03$ (1SD, $n=3$, excluding one outlier) for Sri Lanka (Data Table SL1).

However, "external" Sr that differs in its $\delta^{88} \mathrm{Sr}$ from local bedrock (Vollstaedt and others, 2014) can be delivered to the Critical Zone in appreciable amounts by carbonate-rich dust. Given that carbonate minerals are rich in $\mathrm{Sr}$, their potential contribution has to be accounted for the Sr isotope composition of the weathering parent material. The isotope signature of this composite parent material is hereafter referred to as $\delta_{\text {parent }}^{S r}$ (for a list of mathematical terms used in this contribution, see table 1$)$. In particular at the Sri Lanka site carbonate dust input is significant (Hewawasam and others, 2013; Schuessler and others, 2018). Using a combination of elemental and ${ }^{87} \mathrm{Sr} /{ }^{86} \mathrm{Sr}$-based mass balances we provide an estimate of $\delta_{\text {parent }}^{\text {Sr }}$ that includes dust input of $0.09 \pm 0.03 \%$ o (68 \% confidence interval; table 2) for Sri Lanka (Appendix C). As shown in our previous study on the Sierra Nevada site (Uhlig and others, 2017), no such correction is required there given the negligible contribution of dust to the regolith profile $\left(\delta_{\text {parent }}^{S r}=0.35 \pm 0.01 \%\right.$; table 2$)$. For the Alps, ${ }^{87} \mathrm{Sr} /{ }^{86} \mathrm{Sr}$ ratios (fig. 3) and elemental mass balances (Appendix $\mathrm{C}$ ) both suggest that the contribution of carbonate to the studied regolith profiles is negligible, such that $\delta_{\text {parent }}^{S r}$ can be estimated to be $0.23 \pm 0.03 \%$ o there (table 2). However, the strong enrichment of $\mathrm{Ca}, \mathrm{Mg}$, and $\mathrm{Sr}$ in some stream water samples suggests that in the Alps rock carbonate delivers $\mathrm{Sr}$ at the watershed scale (von Blanckenburg and others, 2021). Taken together, in the Alps we do not correct rock and regolith for dust input. However, a correction of stream dissolved $\mathrm{Sr}$ abundance and isotope composition is required to allow for a comparison of the stream data with regolith data (Appendix $\mathrm{C}$ ).

We have thus determined as control (1): the isotope ratios of the parent material set the baseline on isotope signatures in the weathering zone. In the next section we quantify control (2), the isotope fractionation factors.

\section{Strontium Isotope Fractionation Factors}

Isotope fractionation during formation of secondary weathering products. - Sr isotopes have been suggested to fractionate during formation of secondary weathering products (Chao and others, 2015). Direct evidence exists for such fractionation for carbonate formation (for example, Rüggeberg and others, 2008; Böhm and others, 2012; Al- 
TABLE 1

List of stable isotope and flux variables used in this and in other contributions in the same journal issue (Frings and others, 2021a,b)

\begin{tabular}{|c|c|c|c|}
\hline Name & Description & $\begin{array}{l}\text { Relevant } \\
\text { equation(s) in } \\
\text { this study }\end{array}$ & $\begin{array}{c}\text { Difference in } \\
\text { terminology from } \\
\text { Bouchez and others } \\
(2013)\end{array}$ \\
\hline \multicolumn{4}{|c|}{ Isotope composition of the metal $X$ in Critical Zone compartments } \\
\hline$\delta_{\text {diss }}^{X}$ & Dissolved load (soil water, river water) & $(1),(2),(5),(9)$ & None \\
\hline$\delta_{\text {sec }}^{X}$ & Secondary weathering products (clays, oxides) & (1) & None \\
\hline$\delta_{\text {veg }}^{X}$ & Vegetation & (2) & None \\
\hline$\delta_{\text {parent }}^{X}$ & Parent material (rock plus/or dust) & $(5),(9)$ & $\delta_{\text {rock }}^{X}$ \\
\hline$\delta_{\text {solid }}^{X}$ & Bulk solids (soil, river sediment) & $(9)$ & $\delta_{\text {sed }}^{X}$ \\
\hline \multicolumn{4}{|c|}{ Isotope fractionation factors of metal X in Critical Zone processes } \\
\hline$\varepsilon_{\text {prec }}^{X}$ & Formation of secondary products & $(1)$ & $\Delta_{\text {prec }}^{X}$ \\
\hline$\varepsilon_{u p t}^{X}$ & Biological uptake & (2) & $\Delta_{u p t}^{X}$ \\
\hline \multicolumn{4}{|c|}{$\begin{array}{l}\text { Relative partitioning of the metal } X \text { into Critical Zone compartments } \\
\text { relative to its release from primary minerals }{ }^{b}\end{array}$} \\
\hline$f_{\text {sec }}^{X}$ & Into secondary products & $(3)$ & $e_{\text {sec }}^{X} / s_{\text {prim }}^{X}$ \\
\hline$f_{\text {org }}^{X}$ & Into organics (living biota plus litter) & (5) & $e_{\text {org }}^{X} / s_{\text {prim }}^{X}$ \\
\hline$f_{\text {diss }}^{X}$ & Into dissolved load & & \\
\hline$s_{\text {org }}^{X}$ & Release from litter to solution & $(6)$ & None \\
\hline \multicolumn{4}{|c|}{ Export fluxes of $X$ from the Critical Zone relative to total supply } \\
\hline$w^{X}$ & Dissolved export & $(8)$ & None \\
\hline$e^{X}$ & Solid export & & None \\
\hline$e_{\text {prim }}^{X}$ & Export of primary minerals & & None \\
\hline
\end{tabular}

Derived from the approach initially developed in Bouchez and others (2013), the terminology has been slightly amended to account for newer developments. For the definition of element-based metrics used in our study and the companion papers of Frings and others (2021a,b), the reader is referred to the table 1 of von Blanckenburg and others (2021).

Footnotes:

${ }^{\mathrm{a}}$ The $\Delta_{\mathrm{j}-\mathrm{i}}^{\mathrm{X}}$-notation used in Bouchez and others (2013) is better suited to describe a measured isotope difference between two compartments $\left(\delta_{\mathrm{j}}^{\mathrm{X}}-\delta_{\mathrm{i}}^{\mathrm{X}}\right)$. Bouchez and others (2013) show that only at steady state, $\Delta_{\mathrm{sec}-\mathrm{diss}}^{\mathrm{X}}=\varepsilon_{\text {prec }}^{\mathrm{X}}$ and $\Delta_{\text {org-diss }}^{\mathrm{X}}=\varepsilon_{\text {upt }}^{\mathrm{X}}$.

$\mathrm{b}$ These variables denote elemental fluxes normalized to the release flux from primary minerals.

c These variables denote elemental fluxes normalized to the total elemental flux comprising regolith production (as in Bouchez and others, 2013).

Khatib and Eisenhauer, 2016; Shalev and others, 2017). However, the pH recorded for the small streams at all sites (5-6.5), together with the relatively low LOI and Ca content of the soils and XRD spectra (von Blanckenburg and others, 2021) at all sites argue for the absence of pedogenic carbonates.

Adsorption of Sr onto mineral- and organic surfaces, as well as (hydr)oxide and clay formation may lead to Sr stable isotope fractionation, an effect that has not yet been quantified, or has been shown to be ineffective (Bullen and Chadwick, 2016). We first evaluate the isotope fractionation during adsorption of $\mathrm{Sr}$, as along the erodosequence the exchangeable pool is sizeable (Data Table E). In Sri Lanka, the exchangeable Sr pool yields the same $\delta^{88} \mathrm{Sr}$ composition within uncertainty as soil water (in topsoil) and as bulk soil and other extracts in the corestone and saprolite samples (fig. 4). Therefore at this site adsorption of exchangeable $\mathrm{Sr}$ does not appear to induce 
TABLE 2

Strontium stable isotope composition, field-derived estimates of isotope fractionation factors, and fluxes amongst compartments of the Critical Zone along the erodosequence. See references to equations for their calculation

\begin{tabular}{|c|c|c|c|c|}
\hline & Alps & Sierra Nevada & Sri Lanka & Note \\
\hline \multicolumn{5}{|c|}{ Isotope composition of Critical Zone compartments } \\
\hline$\delta_{\text {parent }}^{\text {Sr }}$ & $0.23 \pm 0.03$ & $0.35 \pm 0.01$ & $0.09 \pm 0.03$ & $a$ \\
\hline$\delta_{\text {sec }}^{S r}$ & 1 & 1 & $-0.14 \pm 0.04$ & $b$ \\
\hline$\delta_{v e g}^{S r}$ & $0.12 \pm 0.10$ & $-0.02 \pm 0.27$ & $0.12 \pm 0.07$ & $c$ \\
\hline$\delta_{\text {diss }}^{S r}$ & $(0.39 \pm 0.15)$ & $0.32 \pm 0.03$ & $0.18 \pm 0.13$ & $d$ \\
\hline$\delta_{\text {solid }}^{\text {Sr }}$ & $0.27 \pm 0.01$ & $0.37 \pm 0.01$ & $0.07 \pm 0.02$ & $e$ \\
\hline$\delta_{\text {diss }}^{S r}-\delta_{\text {parent }}^{S r}$ & $(0.16 \pm 0.15)$ & $-0.03 \pm 0.03$ & $0.09 \pm 0.13$ & $f$ \\
\hline \multicolumn{5}{|c|}{ Isotope fractionation factors } \\
\hline$\varepsilon_{\text {prec }}^{S r}($ equation 1$)$ & / & 1 & $-0.32 \pm 0.13$ & $g$ \\
\hline$\varepsilon_{u p t}^{S r}($ equation 2$)$ & $(-0.27 \pm 0.18)$ & $-0.34 \pm 0.23$ & $-0.06 \pm 0.15$ & $h$ \\
\hline \multicolumn{5}{|c|}{ Flux-derived flux variables } \\
\hline$f_{\text {sec }}^{S r}($ equation 3$)$ & $0.16^{+0.24}-0.27$ & $0.07^{+0.25}-0.33$ & $0.02^{+0.02}-0.03$ & $i$ \\
\hline$f_{\text {org }}^{S r}$ & $0.30^{+0.66}-1.76$ & $-0.09^{+0.38}-0.33$ & $0.39^{+0.20}-0.20$ & $j$ \\
\hline$f_{\text {diss }}^{S r}$ & $0.62^{+1.61}-0.67$ & $1.12^{+0.44}-0.61$ & $0.59^{+0.20}-0.19$ & $k$ \\
\hline$D E E_{N a}^{S r}$ (equation 4) & $0.69^{+1.75}-0.66$ & $1.22^{+0.78}{ }_{-0.46}$ & $0.61^{+0.20}-0.19$ & $l$ \\
\hline $\operatorname{Rec}^{\mathrm{Sr}}$ & $0.05^{+0.04}-0.03$ & $0.80^{+0.63}-0.42$ & $6.4^{+4.6}-3.6$ & $m$ \\
\hline$s_{\text {org }}^{S r}$ (equation 6) & $-0.23^{+1.85}-0.65$ & $0.93^{+0.99}{ }_{-0.66}$ & $6.0^{+4.3}-3.6$ & $n$ \\
\hline$w^{S r}($ equation 8$)$ & $0.59^{+1.30}-0.56$ & $1.01^{+0.34}-0.29$ & $0.60^{+0.20}-0.20$ & $o$ \\
\hline$e_{\text {prim }}^{\text {Sr }}($ equation 10$)$ & $-0.28^{+0.20}-0.49$ & $-0.34^{+0.17}-0.16$ & $-0.02^{+0.02}-0.03$ & $p$ \\
\hline \multicolumn{5}{|c|}{ Isotope-derived flux variables } \\
\hline$f_{\text {org }}^{\text {Sr }}$ (equation 5) & $0.44^{+0.89}-0.45$ & $-0.07^{+0.08}-0.15$ & $0.11^{+1.76}-1.43$ & $q$ \\
\hline$w^{S r}$ (equation 9) & $\left(0.14^{+1.90}{ }_{-1.62)}\right.$ & $0.51^{+0.69}{ }_{-0.89}$ & $0.52^{+1.46}-1.20$ & $r$ \\
\hline
\end{tabular}

All uncertainties are reported here as $68 \%$ confidence intervals.

${ }^{2}$ Estimated from the average and standard deviation of $\delta^{88} \mathrm{Sr}$ values obtained on all available rock samples for each site (one for the Alps, hence uncertainty corresponds to analytical 1SD; one for Sierra Nevada for which only one measurement was available, hence uncertainty corresponds to the 1SD of repeated measurements of the basalt reference material BHVO-2; three for Sri Lanka where one sample with a much lower $\delta^{88} \mathrm{Sr}$ value was excluded; Data Tables A1, SN1, and SL1).

${ }^{\mathrm{b}}$ Estimated from the average and standard deviation of $\delta^{88} \mathrm{Sr}$ values obtained on two clay-sized separates from the same samples for Sri Lanka (Data Table SL1). Estimate is impossible for the Alps and Sierra Nevada because of the absence of any measurable pool of secondary weathering products there.

${ }^{c}$ Estimated from the average and standard deviation of $\delta^{88} \mathrm{Sr}$ values obtained on all available vegetation samples (three for the Alps, six for Sierra Nevada, eight for Sri Lanka) for each site (Data Tables A3, SN3, and SL3).

${ }^{\mathrm{d}}$ Estimated from the average and standard deviation of dissolved $\delta^{88} \mathrm{Sr}$ values obtained in small stream samples (excluding D102) for Sierra Nevada (Data Table SL2) and in small stream samples (excluding the larger Uma Oya) in Sri Lanka (Data Table SL2). Note that the estimate for the Alps (in italics) is strongly biased because the carbonate contribution is impossible to correct for (Appendix C).

${ }^{\mathrm{e}}$ Estimated from the average and standard deviation of $\delta^{88} \mathrm{Sr}$ values obtained on selected top soil samples for each site (three regolith samples for the Goms profiles for the Alps; one top soil sample for Sierra Nevada for which only one measurement was available, hence uncertainty corresponds to the $1 \mathrm{SD}$ of repeated measurements of the basalt reference material BHVO-2; two top soil samples for Sri Lanka; Data Tables A1, SN1, and SL1).

${ }^{I}$ Calculated using the average $\tau_{\mathrm{Sr}}$ and $\tau_{\mathrm{Ca}}$ values of the A horizons of the Goms profiles B1, B2, B4, B4, and B6 for the Alps; of the uppermost three saprolite samples augered in the P301 catchment for Sierra Nevada; and of the five uppermost saprolite samples from the Hakgala profile of Sri Lanka (all data from von Blanckenburg and others, 2021).

${ }^{1}$ From von Blanckenburg and others (2021).

${ }^{\mathrm{m}}$ From von Blanckenburg and others (2021).

${ }^{\circ}$ Calculated using the same estimates as in notes (a) and (d) for dissolved and rock $\mathrm{Sr} / \mathrm{Na}$ ratios and $\tau_{\mathrm{Na}}$ values.

$\mathrm{d}, \mathrm{f,h}, \mathrm{r}$ Note that the estimate for the Alps (between parentheses) is strongly biased because of the carbonate contribution to the stream dissolved load composition is impossible to correct for (Appendix C).

${ }^{\mathrm{a}-\mathrm{h}}$ Uncertainty is assumed to be symmetric because it is directly derived from analytical uncertainty.

$\mathrm{f}, \mathrm{h}, \mathrm{r}$ Uncertainty estimated through Gaussian error propagation.

${ }^{i-r}$ Note that the central estimates correspond to the median $\left(D_{50}\right)$ of the distribution obtained for Monte Carlo simulations with 5,000 runs. Uncertainty was also assessed using the $\mathrm{D}_{16}$ and $\mathrm{D}_{84}$ of these distributions (von Blanckenburg and others, 2021). 
resolvable isotope fractionation. In the Sierra Nevada, we observe lower $\delta^{88} \mathrm{Sr}$ in the exchangeable fraction of the upper saprolite than in stream water. However, these values are very close to those of the soil water from overlying horizons (fig. 4). We interprete this close agreement to indicate infiltration of soil water to lower layers without isotope fractionation. Finally, at the Goms site in the Alps, a $\delta^{88} \mathrm{Sr}$ value for the $\mathrm{H}_{2} \mathrm{O}$-soluble extract that is $\sim 0.1 \%$ lower than that of the bulk exchangeable value of the corresponding upper soil horizon is observed. Nevertheless, this extract also displays a high $\mathrm{K} / \mathrm{Na}$ ratio, which might indicate release of $\mathrm{Sr}$ from litter. As a consequence the $\mathrm{Sr}$ source of this exchangeable extract is likely the overlying vegetation which displays a similar $\delta^{88} \mathrm{Sr}$ value (fig. 4). Altogether, our data do not argue for appreciable Sr isotope fractionation during adsorption of Sr onto the exchange complex along the erodosequence, rendering this process unlikely to shift $\delta^{88} \mathrm{Sr}$ in soil and stream water.

We evaluate next whether the incorporation of Sr into clays or oxides leads to isotope fractionation. We were not able to access the Sr isotope composition of the (hydr) oxide pool because of lack of sufficient amounts of Sr in those leachates. Sr isotopes in clay-sized separates could be measured only for the Sri Lanka profile (figs. 3 and 4). We thus provide an estimate for $\varepsilon_{\text {prec }}^{S r}$, the Sr stable isotope fractionation factor associated with Sr incorporation into clays for Sri Lanka only. To this end we make use of the mass balance assumption that fluxes in our eroding sites are at steady-state. In this case isotope differences between exchanging compartments are equal to the fractionation factor (Bouchez and others 2013):

$$
\varepsilon_{\text {prec }}^{S r}=\delta_{\text {sec }}^{S r}-\delta_{\text {diss }}^{S r}
$$

where $\delta_{s e c}^{S r}$ and $\delta_{\text {diss }}^{S r}$ are the $\delta^{88} \mathrm{Sr}$ composition of the secondary phase formed and of the dissolved Sr exported from the weathering zone, respectively. Using the average of the $\delta^{88} \mathrm{Sr}$ values obtained for two clay-sized separates to estimate $\delta_{s e c}^{S r}$, combined with the average riverine dissolved Sr composition for $\delta_{d i s s}^{S r}$, the best estimate we obtain

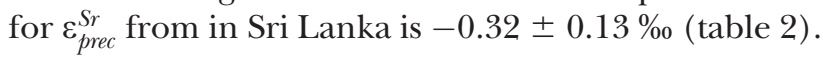

This analysis provides the first quantitative constraint on Sr stable isotope fractionation for the formation of secondary weathering products in the Critical Zone. However, as shown below, secondary solid formation is small in terms of Sr fluxes along the erodosequence, and is thus unlikely to provide a viable explanation for the relatively high $\delta^{88} \mathrm{Sr}$ values found for $\mathrm{Sr}$ in stream waters in the erodosequence. This finding differs from that suggested by previous studies (Wei and others, 2013; Chao and others, 2015; Shalev and others, 2017). Therefore, and as suggested by Andrews and Jacobson (2016), biological uptake appears to be the much stronger driver of $\mathrm{Sr}$ stable isotopes in the Critical Zone.

Isotope fractionation during plant uptake.-Only few studies have shown that plants preferentially take up the light isotopes of Sr (de Souza and others, 2010; Bullen and Chadwick, 2016; Guilbourdenche and others, 2020; Oeser and von Blanckenburg, 2020a). To complement this initial set of isotope fractionation factors during plant uptake of $\operatorname{Sr}\left(\varepsilon_{u p t}^{S r}\right)$ we again revert to the steady state mass balance allowing for the derivation of isotope fractionation factors from differences in isotope ratios (Bouchez and others 2013):

$$
\varepsilon_{u p t}^{S r}=\delta_{v e g}^{S r}-\delta_{d i s s}^{S r}
$$

where $\delta_{\text {veg }}^{S r}$ is the $\delta^{88} \mathrm{Sr}$ of plants. In the absence of constraints on the relative contribution of $\mathrm{Sr}$ in the various plant parts to total plant mass - as well as measurements of root mass and its Sr concentration - we take the simple average of all $\delta^{88} \mathrm{Sr}$ values measured on plants at a given site as an estimate of the local $\delta_{v e g}^{S r}$. We acknowledge 
that this approach neglects any potential intra-plant fractionation, as observed for Sr isotopes by de Souza and others (2010), Bullen and Chadwick (2016), and Oeser and von Blanckenburg (2020a).

For the Swiss Alps sites, measurements of $\delta^{88} \mathrm{Sr}$ in plant samples are available only for the Aare site $(0.12 \pm 0.10 \%)$, and stream water $\delta^{88} \mathrm{Sr}$ composition could not be corrected for non-silicate inputs (Appendix C; $0.39 \pm 0.15 \%$ ). Consequently, stream water $\delta^{88} \mathrm{Sr}$ may not reflect the $\mathrm{Sr}$ that is available to plants growing on granitic substrate, and the estimate of $\varepsilon_{u p t}^{S r}(-0.27 \pm 0.18)$ at this site needs to be treated with caution.

In the Sierra Nevada, two groups of plants can be singled-out based on their $\mathrm{Sr}$ isotope signatures (fig. 3). High-standing trees (Pinus Ponderosa and Pinus Jeffreyi) have higher radiogenic ${ }^{87} \mathrm{Sr} /{ }^{86} \mathrm{Sr}$ ratios (around $0.7080-0.7082$ ) than shrubs (Ceanothus cordulatus and Arctostaphylos Manzanita, around 0.7076-0.7077; fig. 3), regardless of whether leafy or woody parts are considered. Because the ${ }^{87} \mathrm{Sr} /{ }^{86} \mathrm{Sr}$ ratio traces source and not isotope fractionation, this means that the $\mathrm{Sr}$ source differs between these plant species, for example by roots tapping different depth intervals (Uhlig et al., 2020). The lower ${ }^{87} \mathrm{Sr} /{ }^{86} \mathrm{Sr}$ ratios of shrubs are closer to those of top soil water (fig. 3). Although their sampling sites are not exactly the same, these plants also differ in their $\delta^{88} \mathrm{Sr}$ (fig. 4), with pines yielding higher $\delta^{88} \mathrm{Sr}(0.16 \pm 0.15 \%$ o) than shrubs $\left(-0.21 \pm 0.06 \%\right.$; Data Table SN3). We use the average $\delta^{88}$ Sr composition of all plant samples $(-0.02 \pm 0.23 \%$ ) and the average composition of the local stream dissolved $\operatorname{Sr}(0.32 \pm 0.06 \%)$, yielding an estimate for $\varepsilon_{u p t}^{S r}$ of $-0.34 \pm 0.23 \%$ for Sierra Nevada.

In Sri Lanka, plant ${ }^{87} \mathrm{Sr} /{ }^{86} \mathrm{Sr}$ ratios overlap with those observed in bulk topsoil (fig. 3) which is thus the source of Sr to plants. This assumption is consistent with the complete Sr depletion observed through most of the profile. Also $\delta^{88} \mathrm{Sr}$ in bulk topsoil is identical to plants within uncertainty $(0.07 \pm 0.03 \%$; Data Tables SL1 and SL3). Soil water and exchangeable Sr pools have overlapping $\delta^{88} \mathrm{Sr}$ values (fig. 4; Data Tables SL1 and SL2). The average river river dissolved $\delta^{88} \mathrm{Sr}$ is $0.18 \pm 0.13 \%$. The eight plant samples from Sri Lanka also overlap in their $\delta^{88} \mathrm{Sr}$ and have an average of $0.12 \pm 0.07 \%$. This leads to an isotope fractionation factor during plant uptake $\varepsilon_{u p t}^{S r}$ that is essentially zero within uncertainty $(-0.06 \pm 0.15 \%$ o).

Altogether, our estimates for the $\mathrm{Sr}$ isotope fractionation factor during plant uptake is $-0.34 \pm 0.23 \%$ for Sierra Nevada and $-0.06 \pm 0.15 \%$ for Sri Lanka. We emphasize that at both these sites the fractionation factor is subject to a substantial degree of uncertainty that arises from the method used for these estimates, and from the data on which we rely (for example, the samples may not be considered to be truly representative). Yet they are consistent with values obtained at the site of the Damma Glacier in Switzerland (de Souza and others, 2010), those calculated from soil exchangeable $\mathrm{Sr}$ and plant $\mathrm{Sr}$ isotope composition along a soil "climosequence" in Hawaii (Bullen and Chadwick, 2016), and are essentially identical to those obtained between the soil bio-available Sr fraction and plants in the Chilean Coastal Cordillera (Oeser and von Blanckenburg, 2020a). The fact that virtually no isotope fractionation is observed for the tropical rain forest in Sri Lanka is consistent with previous findings on $\mathrm{Mg}$ stable isotopes at the same site (Schuessler and others, 2018). We note that taxon-specific isotope fractionation has been reported for other metals in organisms (for example, Fe: Guelke and von Blanckenburg, 2007; and Mg: Bolou-Bi and others, 2010; Pokharel and others, 2018), linked to different strategies of nutrient acquisition. Therefore, the fact that the dominant plant types and ecosystems vary between the sites (temperate montane shrubs and conifers in Sierra Nevada, and tropical forest in Sri Lanka) offers a potential explanation for the different values of $\varepsilon_{u p t}^{S r}$. In addition, for a given species, plant uptake strategies might vary with nutrient availability or 
climatic conditions. For example, in Sri Lanka a "direct uptake" path from high-quality litter might prevail, engineered for instance by arbuscular mycorrhizal fungi that dominate tropical forests (Hättenschwiler and others, 2011), and that directly extract elements from leaf litter, thereby bypassing the dissolved Sr pool which could alternatively be fed during bacterial litter remineralization (Schuessler and others, 2018).

Regardless of the still widely unknown controls over Sr fractionation by plant uptake, our analysis shows for the first time that in the Critical Zone Sr isotopes can be fractionated by two categories of processes (defined as control (2) in our introduction): incorporation into clay minerals and biological uptake, both preferring the light $\mathrm{Sr}$ isotopes over the heavy ones. However, such fractionation will only have leverage to set the isotope composition of the dissolved load if $\mathrm{Sr}$ fluxes result in sufficient Sr separation between compartments (condition (3) in the introduction; Bouchez and others, 2013). In the following section we thus turn towards the quantification of these Sr fluxes amongst Critical Zone compartments.

\section{Flux of Strontium into Secondary Weathering Products}

We first evaluate whether the offset in $\delta^{88} \mathrm{Sr}$ between the dissolved Sr pool and that of the parent material results from Sr incorporation into (hydr)oxides and clay minerals. A first way to appraise the fluxes involved is to quantify the fraction of bulk regolith Sr that is hosted by such secondary phases. Sr bound to Fe-Al-(hydr)oxides is around $0.5 \%$ in the regolith samples of the Sierra Nevada site, and 1 to $2.5 \%$ in the corestone samples of the Sri Lanka site (Data Table E). Clay-sized material typically hosts $0.1 \%$ of bulk Sr (excluding separation performed on the Sri Lanka corestone that contained fine-grained, primary minerals containing Sr; Data Table E). These quantities appear negligible. Nevertheless, even the formation of a small amount of Sr-bearing secondary phases in Sri Lanka may result in a measurable isotope effect on the $\delta^{88} \mathrm{Sr}$ in bulk regolith given that the loss of $\mathrm{Sr}$ from primary minerals is almost complete (fig. 5). We also note that the settling-based separation of clay-sized material might under-estimate clay-bound $\mathrm{Sr}$ if large clay aggregates settle during the separation and thus remain undetected. Overall, at first sight the $\mathrm{Sr}$ amounts found in secondary solids appear to exert negligible leverage for isotope fractionation.

However, the relative net flux of $\mathrm{Sr}$ into secondary solids divided by the $\mathrm{Sr}$ release flux from primary minerals in the regolith (effect (3) in the introduction), rather than the Sr amounts in a given compartment, is the parameter that is critical for the stable isotope ratio of the involved compartments. (Here "net" refers to Sr precipitation minus Sr re-dissolution; Bouchez and others, 2013). We call this term $f_{s e c}^{S r}$. Note that this term is equivalent to the ratio $e_{s e c}^{S r} / s_{\text {prim }}^{S r}$ introduced by Bouchez and others (2013), that is the removal of $\mathrm{Sr}$ bound to secondary phases by erosion $\left(e_{s e c}^{S r}\right)$ relative to the Sr release flux from the partial dissolution of primary minerals $\left(s_{\text {prim }}^{\mathrm{Sr}}\right)$. Indeed, physical removal from the regolith by erosion is the most obvious way to prevent such isotopically-fractionated secondary solids from re-dissolution. $f_{s e c}^{S r}$ can be estimated from the depletion of $\mathrm{Sr}$ across the regolith relative to the depletion of a fully soluble element (for example, an element not retained in secondary weathering products, here we use $\mathrm{Ca}$ ). This estimates requires making two assumptions: i) Sr and $\mathrm{Ca}$ are hosted by the same primary minerals; ii) Sr and Ca are released from primary minerals in a congruent way, meaning without elemental fractionation upon primary mineral dissolution:

$$
f_{s e c}^{S r}=1-\frac{\tau_{S r}}{\tau_{C a}}
$$




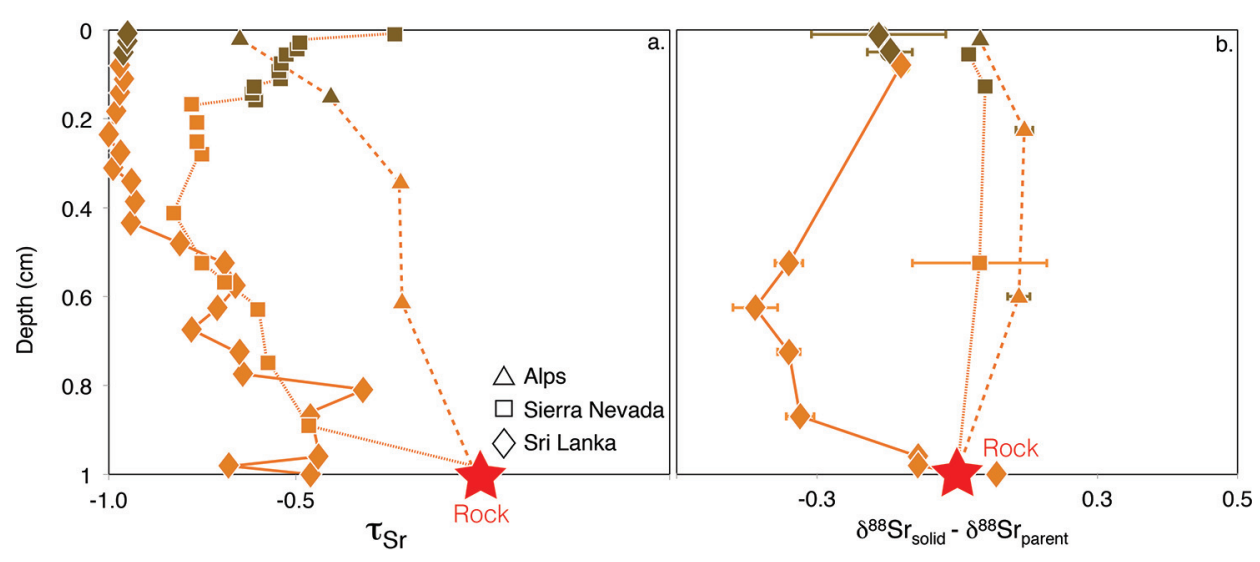

Fig. 5. Sr mass transfer coefficient $\left(\tau_{\mathrm{Sr}}\right.$, panel a) and parent-corrected "stable" isotope ratios $\left(\delta^{88} \mathrm{Sr}_{\text {solid }}-\delta^{88} \mathrm{Sr}_{\text {parent }}\right.$, panel b) as a function of normalized depth (that is, depth divided by regolith thickness) in the regolith profiles along the erodosequence. By definition, the rock composition plots at the coordinates $(1,1)$ and $(0,1)$ in panel a and $b$, respectively (the local rock composition was used as the estimate for $\delta^{88} \mathrm{Sr}_{\text {parent; }}$ potential dust inputs were not taken into account; see Appendix C).

$f_{\text {sec }}^{S r}$ denotes that flux fraction of $\mathrm{Sr}$ that, unlike Ca, is locked and then potentially eroded in secondary solids. Even if these solids accumulate in the regolith during a transient state, rather than getting eroded, the mass balance approach of Bouchez and others (2013) used here is still valid.

To quantify the $\tau$-values to be used in equation (3) we used the regolith sample at the point where the formation of secondary weathering products is the most advanced, while the influence of biological cycling is still minimal. The composition of the upper saprolite is representative of this condition.

Estimates of $f_{\text {sec }}^{\text {Sr }}$ are $0.16^{+0.24}-0.27$ in the Alps, $0.07^{+0.25}-0.33$ for Sierra Nevada, and $0.02^{+0.02}-0.03$ in Sri Lanka (table 2; fig. 6). These numbers indicate only limited formation of Sr-bearing secondary weathering products along the erodosequence. Such minor Sr fluxes into secondary weathering products imply that the Sr depletion in bulk regolith can be interpreted solely in terms of primary mineral dissolution. The regolith $\tau_{\mathrm{Sr}}$ values that increase from Sri Lanka to Sierra Nevada to the Alps (figs. 2 and 5) indicate decreasing Sr depletion along the gradient and thus reflect kinetic limitation on mineral dissolution, imposed by decreasing regolith residence time (West and others, 2005; Dixon and others, 2012). The flux of Sr release from the regolith, $W_{\text {regolith }}^{\text {Sr }}$ (von Blanckenburg and others, 2021), is highest in Sierra Nevada even though amongst the erodosequence this site features intermediate regolith residence time (von Blanckenburg and others, 2021). We interpret this apparent contradiction to result from the fast supply of fresh minerals in Sierra Nevada. Such fast supply is indeed likely to sustains a high Sr release flux from the regolith at this site.

The fast supply of dissolved Sr from primary minerals in Sierra Nevada would also favor the formation of Sr-bearing secondary weathering phases. Indeed, Sr incorporation into secondary weathering products, although small and associated with significant uncertainty, is most prominent in the Sierra Nevada. This behavior is consistent with the "boomerang" or "croissant" relationship between the formation of secondary weathering products hypothesized by Bouchez and others (2013) and observed for Li, $\mathrm{Si}$, and $\mathrm{K}$ at the scale of large rivers (Dellinger and others, 2015; Frings and others, 2016; Li and others, 2019). According to this prediction the formation of Sr-bearing secondary products is hampered when the residence time of solid material in the Critical Zone is short, as dictated by fast erosion and thin regolith (Alps). Conversely, 
Sr-bearing clays undergo re-dissolution in contact with undersaturated pore waters in the uppermost horizons of the regolith (Golla and others, 2021) if the residence time is long, which is the case at low erosion rates and thick regolith (Sri Lanka).

In any case the main finding of this analysis is that the overall small relative amount of Sr transferred into secondary weathering products is unlikely to influence the signature of the dissolved Sr exported by isotope mass balance. Sr biological cycling is the isotopically relevant process along the erodo-sequence. We quantify the associated $\mathrm{Sr}$ fluxes in the next section.

\section{Biological Uptake Flux of Strontium}

The net formation and removal of strontium-bearing organic material.-Although $\mathrm{Sr}$ is not an essential nutrient per se, it is still utilized by higher plants. A simple explanation is the biogeochemical similarity between $\mathrm{Sr}$ and $\mathrm{Ca}$, which is a macro nutrient to plants (Rediske and Selders, 1953; Gupta and others, 2018; Burger and Lichtscheidl, 2019). For a bio-derived isotopic signature to be preserved in the complementary dissolved product, a fraction of the element initially taken up by plants in a fractionated form needs to be preserved and removed in solid organic matter rather than being made available for renewed recycling after litter remineralization (Bouchez and others, 2013; Uhlig and others, 2017; Charbonnier and others, 2020). In other words, the preservation, or "net" formation of organic material containing Sr is what sets these isotope signatures.

Again, we can use an independent mass balance method to constrain this isotope partitioning. Essentially, if a fraction of an element $X$ released from parent material is partitioned into organic solids without return into the dissolved load a deficit in dissolved export will emerge. This deficit can be quantified by the "Dissolved Export Efficiency" $D E E_{N a}^{S r}$ introduced by Uhlig and others (2017) and calculated by von Blanckenburg an others (2021) for the erodosequence sites:

$$
D E E_{N a}^{S r}=\frac{(S r / N a)_{\text {diss }}}{(S r / N a)_{\text {parent }}} /\left(\frac{\tau_{S r}}{\tau_{N a}}\right)
$$

Essentially, $D E E_{N a}^{S r}$ is the river dissolved flux of an element divided by the net regolith release flux of the same element. A $D E E_{N a}^{S r}$ of 1 means complete transfer of dissolved $\mathrm{Sr}$ from regolith into runoff, a $D E E_{N a}^{S r}<1$ denotes a reduced export efficiency because some solute is retained in organic solids. To account for unknown variations in export flux from variations in runoff $\mathrm{Na}$ is used here as a normalizing element as it is neither sensitive to formation of secondary weathering products in the regolith, nor to biological uptake. Details are provided in von Blanckenburg and others (2021) about how $(\mathrm{Sr} / \mathrm{Na})_{\text {diss }}$ values are corrected from non-silicate inputs (Alps) or how $\mathrm{Sr}$ contribution from dust in included in the estimate of $(\mathrm{Sr} / \mathrm{Na})_{\text {parent }}$ (Sri Lanka); and for the derivation of DEE.

Although we interpret a $D E E_{N a}^{S r}<1$ to indicate preservation and export of Sr contained in plant debris or organic particulates derived thereof, it is important to note that low $D E E_{N a}^{X}$ values can indicate a more general imbalance between release from parent material and export in rivers. Indeed along the erodosequence such imbalance is apparent for many elements (von Blanckenburg and others, 2021), including insoluble, non-plant-utilized metals like Al. Because of the $\mathrm{Na}$ normalization employed such imbalance cannot easily be attributed to changes in runoff. Rather, unlike Na, a part of a "missing dissolved flux" of an element might correspond to a certain amount of this element complexed to organic or inorganic molecules present in a colloidal fraction (Trostle and others, 2017). This fraction might get preferentially exported 

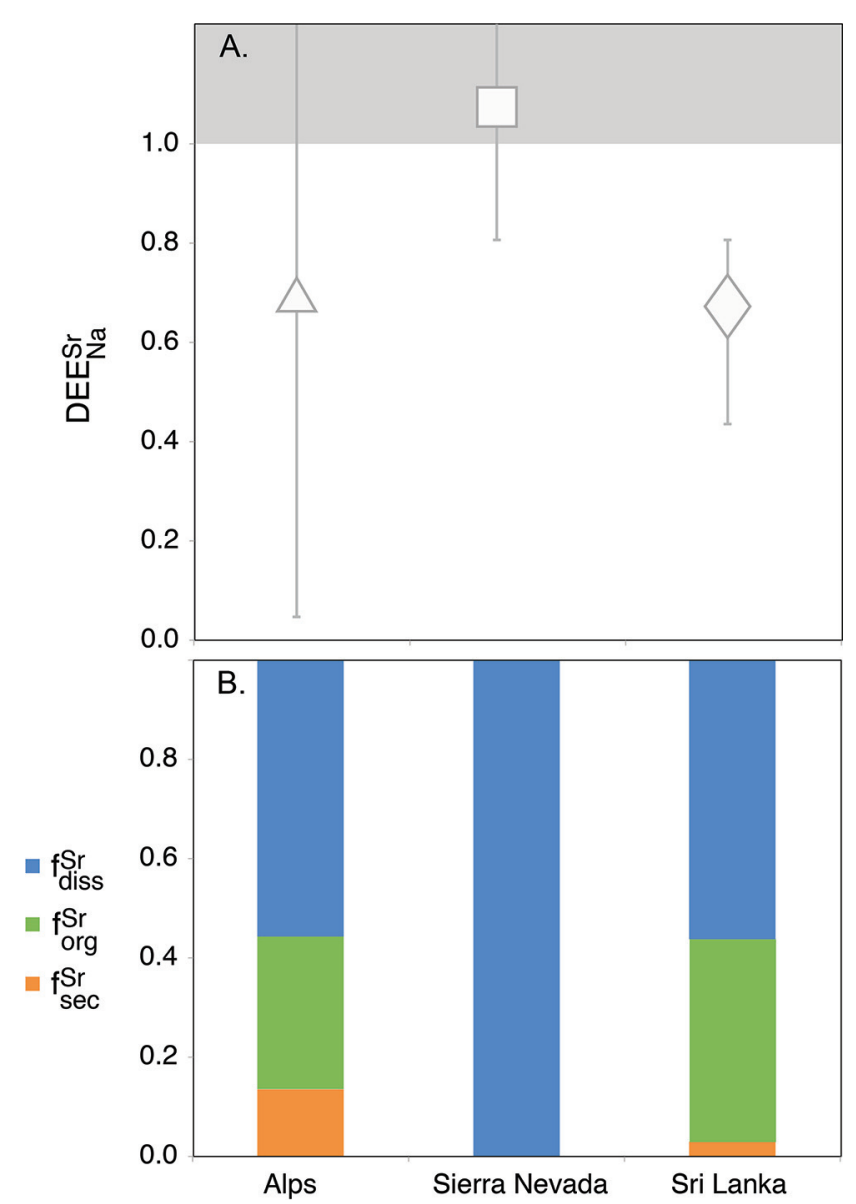

Fig. 6. Sr partitioning in the Critical Zone for the three sites of the erodosequence. (a) The "missing dissolved $\mathrm{Sr}^{\prime \prime}$ is indicated by $D E E_{N a}^{S r}$ (eq 4). The grey field denotes the area of $D E E_{N a}^{s r}$ values $>1$ that cannot be explained at steady state - unless some Sr sources have not been accounted for. (b) The relative fluxes of secondary solid formation $f_{s e c}^{S r}$, uptake into vegetation $f_{\text {org }}^{S r}$, and remaining dissolved fraction $f_{\text {diss }}^{S r}$. Here, only central estimates derived from Monte Carlo calculations are displayed. Negative relative fluxes are not represented.

during flood events that were not fully contained in our stream sampling campaign, and may thus not be accounted for in the dissolved loads. However, $\mathrm{Sr}$ is not prone to complexation to colloids (Trostle and others, 2017). We thus attribute the $D E E_{N a}^{S r}<1$ to be due to erosion of Sr hosted by plant debris.

Calculated values of $D E E_{N a}^{S r}$ are $0.69^{+1.7}{ }_{-0.66}$ for the Alps, $1.2^{+0.8}{ }_{-0.4}$ for Sierra Nevada, and $0.67^{+0.14}-0.25$ for Sri Lanka (von Blanckenburg and others, 2021; fig. 6). We note that these estimates could be biased to some extent by an inaccurate estimate of the source rock composition that is used in equation (4) to calculate $(\mathrm{Sr} / \mathrm{Na})_{\text {parent }}$ (for example, if rocks sampled in the vicinity of the regolith profile may not be representative of those drained by the streams). Similarly, the estimate of the silicatederived $(\mathrm{Sr} / \mathrm{Na})_{\text {diss }}$ in equation (4) could be non-representative if it contains solutes from different bedrock.

We can use this estimate to derive relative net incorporation of $\mathrm{Sr}$ into organic solids $f_{\text {org }}^{S r}$ (analogous to $f_{s e c}^{S r}$ defined in eq 3 ). This flux-derived $f_{\text {org }}^{S r}$ is equal to $1-D E E_{N a}^{S r}$ 
provided that $\mathrm{Sr}$ is not significantly affected by the formation of secondary weathering products in the regolith, as is the case here, as discussed above. Using the values of $D E E_{N a}^{S r}$ above, $f_{\text {org }}^{S r}$ estimates are $0.30^{+0.66}{ }_{-1.76}$ for the Alps, $-0.09^{+0.38}{ }_{0.61}$ for the Sierra Nevada, and $0.39^{+0.20}{ }_{-0.20}$ (table 2; fig. 6 ). The net incorporation - and possibly erosion - of Sr contained in organic solids or in plant debris is thus a significant player of Critical Zone Sr cycling at both the Alps and Sri Lanka sites, whereas it is negligible in the Sierra Nevada.

Estimating biological fluxes of strontium using its isotopes.-Stable $\mathrm{Sr}$ isotope ratios offer an alternative, totally independent means of estimating the values of $f_{\text {org }}^{s r}$. If as is the case for $\mathrm{Sr}$ the role of the formation of secondary weathering products can be neglected, equation (17) from Bouchez and others (2013) becomes:

$$
\text { Isotope-derived } f_{\text {org }}^{S r}=-\frac{\delta_{\text {diss }}^{S r}-\delta_{\text {parent }}^{S r}}{\Delta_{u p t}^{S r}}
$$

Using isotopes, values of $f_{\text {org }}^{S r}$ are $0.44^{+0.89}{ }_{-0.45}$ for the Alps, $-0.07^{+0.08}-0.15$ for Sierra Nevada, and $0.11_{-1.43}^{+1.76}$ for Sri Lanka (note that the large uncertainty for Sri Lanka stems from the low absolute value of $\varepsilon_{u p t}^{S r}$; see above and table 2). These values compare reasonably well to the above-determined, flux-derived $f_{\text {org }}^{S r}$ estimates (fig. 7). (Note that the estimate of $\delta_{\text {diss }}^{S r}$ in the Alps is not corrected for non-silicate inputs (Appendix $\mathrm{C}$ ), and that there we used a putative value for of $\varepsilon_{u p t}^{S r}$ of $-0.27 \pm 0.18$ ). The agreement between these fully independent estimates is remarkable, and lends confidence in our organic matter erosion fluxes. Both elemental and isotope mass balance consistently show how the erosion vs. dissolution (see below) of $\mathrm{Sr}$ in litter or other organic particles varies along the erodosequence, with minimal erosion in Sierra Nevada and maximal erosion in the Alps and in Sri Lanka.

Estimating the release of strontium from litter.- The difference in $f_{\text {org }}^{S r}$ between sites shows that not all Sr taken up by plants is eroded in organic particles. Some of this $\mathrm{Sr}$ is released from organic particles. We can quantify this flux, again relative to $\mathrm{Sr}$ release from primary minerals. This litter dissolution flux is called $s_{\text {org }}^{S r}$. The assumption we make is that all Sr taken up into bulk plants, (quantified relative to released from regolith, called $R e c^{S r}$ eq 12 in von Blanckenburg and others, 2021), is initially returned to the ground by litterfall. In that case:

$$
s_{o r g}^{S r}=R e c^{S r}-f_{o r g}^{S r}
$$

It may appear counterintuitive that $s_{o r g}^{S r}$ can be higher than unity, as $R e c^{S r}$ can be much higher than 1 . The simple explanation is that with several recycling loops $\mathrm{Sr}$ can be equally solubilized from litter several times, such that the organic solubilisation flux becomes a multiple of its release by weathering.

Note that because $R e c^{S r}$ is relative to release from regolith whereas $f_{\text {org }}^{S r}$ is calculated relative to release from primary minerals equation (6) is valid only for elements which are not significantly retained in secondary phases, like Sr. We obtained site-specific bulk ecosystem Sr uptake $R e c^{S r}$ assuming that it depends linearly on biomass growth as estimated from NPP (Net Primary Production of carbon from FLUXNET network; for details see von Blanckenburg and others, 2021). Further assuming that dry biomass consists of $50 \mathrm{wt} \%$ carbon $\left([C]_{\text {plants }}\right)$, and multiplying biomass growth with 


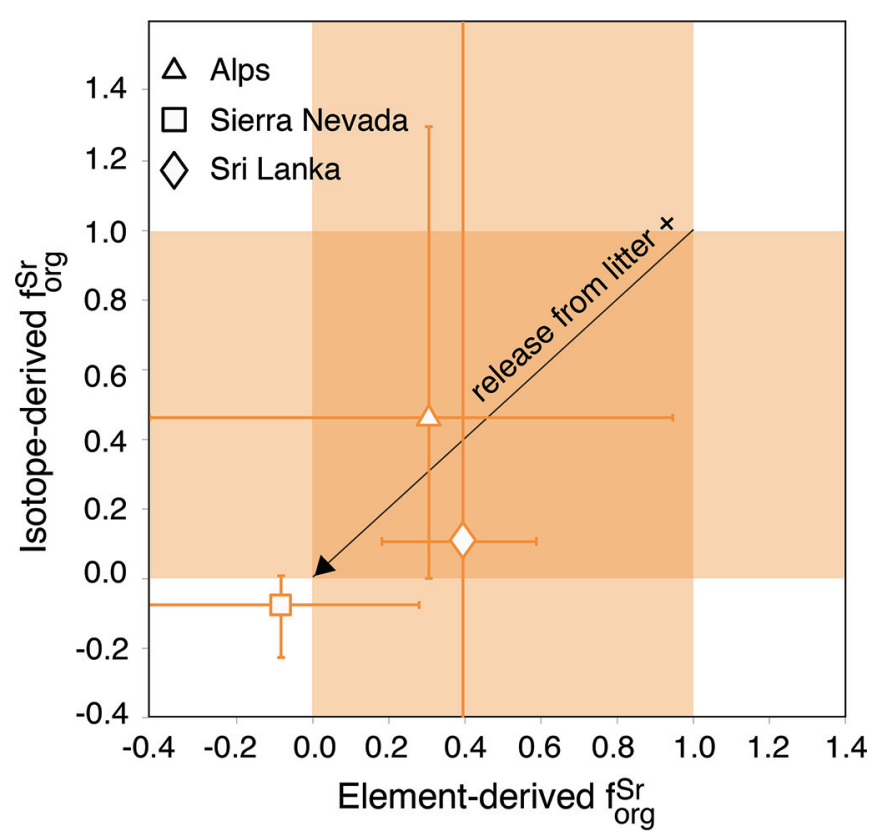

Fig. 7. Comparison between flux-based (X-axis) and isotope-based (Y-axis) estimates of the relative flux of Sr contained in eroded plant debris $f_{\text {org }}^{\text {Sr }}$ (eq 5). The areas shaded in orange denote the limits in flux allowed by the steady state model of Bouchez and others (2013).

the site-specific average Sr concentration in plants $[\mathrm{Sr}]_{\text {plants }}$ (Data Tables A3, SN3, and SL3) we obtained the dimensional Sr biological uptake flux $U^{S r}$ :

$$
U^{S r}=\frac{N P P \times[S r]_{\text {plants }}}{[C]_{\text {plants }}}
$$

Values of $U^{S r}$ are $4.5^{+2.6}{ }^{-3.1} \mathrm{t} \mathrm{km}^{-2} \mathrm{yr}^{-1}$ for the Swiss Alps, $51^{+28}{ }_{-28} \mathrm{t} \mathrm{km}^{-2} \mathrm{yr}^{-1}$ for Sierra Nevada, and $134^{+94}-97 \mathrm{t} \mathrm{km}^{-2} \mathrm{yr}^{-1}$ for Sri Lanka (von Blanckenburg and others, 2021) which corresponds to the gradient in biomass growth along the erodosequence. Corresponding values of $\operatorname{Re} c^{S r}$ are $0.05^{+0.04}-0.03$ for the Swiss Alps, $0.80^{+0.63}-0.42$ for Sierra Nevada, and $6.4^{+4.6}{ }_{-3.6}$ for Sri Lanka (von Blanckenburg and others, 2021; table 2). The increase in relative $\mathrm{Sr}$ uptake from the Alps to Sierra Nevada to Sri Lanka is consistent with findings made for a whole suite of plant-benefitial elements on the same sites (von Blanckenburg and others, 2021), and in particular Mg (Uhlig and others, 2017 and Schuessler and others, 2018). This pattern is also consistent with shifts in nutrient cycling across sites that differ in rock mineral composition (Uhlig and von Blanckenburg, 2019), age (Chadwick and others, 1999), or climate and related biomass production (Oeser and von Blanckenburg, 2020b). Essentially, element recycling is a composite result of geogenic and biogenic factors: in temperate ecosystems underlain by regolith of fast supply by erosion, such as in the Alps and Sierra Nevada, supply by weathering is high whereas biomass growth is low to intermediate. Tropical ecosystems such as Sri Lanka are often underlain by supplylimited and hence strongly nutrient-depleted regolith, yet biomass growth is high due to favourale climatic conditions. The resulting deficit in nutrient supply is compensated for by more efficient nutrient recycling (Uhlig and von Blanckenburg, 2019). 
The $R e c^{S r}$ values for each site can now be used in equation (6) to obtain estimates of $s_{o r g}^{S r}$ along the erodosequence. Values of $s_{\text {org }}^{S r}$ are $-0.23^{+1.85}-0.65$ for the Alps, $0.93^{+0.99}{ }_{-0.66}$ for Sierra Nevada, and $6.0^{+4.3}{ }_{3.6}$ for Sri Lanka (table 2). Although plagued by large uncertainty due to error propagation, these figures show how release of Sr from organic matter is an insignificant process in terms of Sr fluxes in the Alps, becomes relevant in Sierra Nevada, and overwhelming in Sri Lanka.

We have now established the third (3) and last control on stable isotope ratios for $\mathrm{Sr}$, namely the relative $\mathrm{Sr}$ fluxes between the compartments of the Critical Zone. Finally we examine how Sr isotopes partitioning into plants and litter within the Critical Zone sets Sr isotopes signatures in streams.

\section{Export of Strontium from the Critical Zone}

Export of dissolved strontium.-The assesment of export fluxes first requires the estimate of the dissolved Sr flux, relative to total supply to the Critical Zone (or equivalently at steady state, to total export). A first estimate of the dissolved Sr flux $W_{\text {river }}^{X}$ can be obtained from the product of water discharge and dissolved $\mathrm{Sr}$ concentrations in rivers (corrected for carbonate inputs in the Alps; Appendix C), as was compiled by von Blanckenburg and others (2021). Here we normalize these data twice. First, to produce a metric comparable to a "weathering intensity" that we show below to be independently obtainable from an isotope mass balance, we normalise $W_{\text {river }}^{X}$ flux by regolith production of $\mathrm{Sr}, R P^{S r}$ (including dust inputs in Sri Lanka; Appendix C). Second, as done for calculating the $D E E_{N a}^{S r}$ we normalise both $W_{\text {river }}^{X}$ and $R P^{S r}$ to the corresponding fluxes of the fully soluble $\mathrm{Na}$ to account for climate-related variations in discharge. Thus we obtain a first expression of $w^{S r}$, that is an estimate of the relative dissolved Sr export based on elemental measurements only:

$$
\text { Element-based } w^{S r}=\frac{W_{\text {river }}^{S r} /{ }_{R P^{S r}}}{W_{\text {river }}^{N a} /{ }_{R P^{N a}}}=\frac{(S r / N a)_{\text {diss }}}{(S r / N a)_{\text {parent }}}
$$

Note that like $f_{s e c}^{S r}$ or $f_{\text {org }}^{S r}$ defined in the present study, $w^{S r}$ is a relative flux normalized to total regolith production $\left(R P^{S r}\right)$ rather than to Sr release from primary minerals $\left(S_{\text {prim }}^{X}\right)$. Values of $w^{S r}$ are $0.59^{+1.30}{ }_{-0.56}$ in the Swiss Alps, $1.01_{-0.29}^{+0.34}$ in the Sierra Nevada, and $0.60^{+0.20}{ }_{-0.20}$ in Sri Lanka (table 2). These estimates indicate that fractional dissolved $\mathrm{Sr}$ export is greatest in Sierra Nevada and lowest in Sri Lanka and in the Alps. This gradient is exactly the inverse pattern of $f_{\text {org }}^{S r}$ (table 2, fig. 7). This contrast suggests that along the erodosequence Sr storage in organic matter is a main pathway to the prevent the export of Sr as stream dissolved load.

An isotope steady-state mass balance again serves to provide fully independent estimates of the relative fluxes from the weathering zone (Bouchez and others, 2013; Uhlig and others, 2017; Schuessler and others, 2018; Charbonnier and others, 2020):

$$
\text { Isotope-derived } w^{S r}=\frac{\delta_{\text {parent }}^{S r}-\delta_{\text {solid }}^{S r}}{\delta_{\text {diss }}^{S r}-\delta_{\text {solid }}^{S r}}
$$

where $\delta_{\text {solid }}^{\text {Sr }}$ is the $\delta^{88} \mathrm{Sr}$ composition of the bulk solid exported from the Critical Zone. For all sites we use river and topsoil $\delta^{88} \mathrm{Sr}$ data as representative of $\delta_{\text {diss }}^{S r}$ and $\delta_{\text {solid }}^{S r}$, respectively. Note that the value of the isotope-based $w^{S r}$ for the Alps is most likely 
biased because of a significant non-silicate component on $\delta_{\text {diss }}^{S r}$ which is difficult to correct for (Appendix C). Estimates of isotope-based $w^{S r}$ are $0.14^{+1.76}{ }_{-1.62}$ for the Alps, $0.51^{+0.69}-0.89$ for the Sierra Nevada, and $0.52^{+1.46}-1.26$ for Sri Lanka (table 2). Despite the significant uncertainties associated with these estimates, we find that the central estimates of the dissolved $\mathrm{Sr}$ fractional export calculated from elemental budgets and from isotope budgets vary in the same sense along the erodosequence, with lower fractional export in the Alps compared to Sierra Nevada and Sri Lanka (fig. 8). This observation provides confidence on the preferential partitioning of Sr into biological compartments in the Critical Zone, with (a) a strong contribution of release from litter to the dissolved export, and (b) the predominance of organic-bound $\mathrm{Sr}$ on the particulate export.

Export of particulate strontium.-An evaluation of the role of Sr preservation in litter on the stream particulate export flux can also be made. By definition the erosion flux $e^{S r}$ (relative to total element supply to the regolith, $R P^{S r}$ ) is the complement of $w^{S r}$, that is $e^{S r}=1-w^{S r}$. Furthermore, $e^{S r}$ can be split into three contributions: $e^{S r}=e_{p r i m}^{S r}+e_{s e c}^{S r}+e_{o r g}^{S r}$, which reflect the erosion of primary minerals, secondary weathering products, and plant debris, respectively (Bouchez and others, 2013). Defining $f_{\text {diss }}^{S r}=1-f_{\text {sec }}^{S r}-f_{\text {org }}^{S r}$ as the dissolved Sr fraction that remains after some of the Sr released from primary minerals has been partitioned by secondary phase formation and biological uptake (fig. 6), we can calculate:

$$
e_{\text {prim }}^{S r}=f_{\text {diss }}^{S r}\left(-\tau_{S r}\right)-w^{S r} .
$$

In this equation the $\left(-\tau_{S r}\right)$ term transforms $f_{\text {diss }}^{S r}$ into the formation and erosion flux of secondary solids relative to the total Sr supply to the regolith $R P^{S r}$, as are $e_{\text {prim }}^{S r}$ and $w^{S r}$ Calculated values of $e_{\text {prim }}^{S r}$ are $-0.28^{+0.20}{ }_{-0.49}$ for the Alps, $-0.34^{+0.17}-0.16$ for Sierra Nevada, and $-0.02^{+0.02}-0.03$ in Sri Lanka (table 2). Therefore, the particulate export of $\mathrm{Sr}$ as primary minerals is virtually negligible at all sites of the erodosequence. Such a low erosional Sr flux by primary minerals reflects that the Sr-containing primary minerals have mostly been dissolved. The major pathway of $\mathrm{Sr}$ particulate export along the erodosequence is $e_{o r g}^{S r}$. Again this consideration lends support to biological cycling being the most prominent factor in setting $\mathrm{Sr}$ fluxes in the Critical Zone.

\section{Strontium Internal Cycling and Eport along the Erodosequence}

The estimates obtained for Sr fluxes and internal cycling in the Critical Zone along the erodosequence are summarized in figure 9:

- In the Alps, Sr solubilized from regolith has two fates: two thirds of this $\mathrm{Sr}$ are directly drained to aquifers and streams without experiencing any biological cycling at the surface of the regolith. One third of this $\mathrm{Sr}$ is taken up by plants, from which none is released back into solution nor re-utilized by plants. This bio-utilized $\mathrm{Sr}$ is exported in its entirety as particulate organic debris.

- In the Sierra Nevada, plants take up the entirety of the Sr solubilized from regolith. Following uptake and litter fall, Sr release from litter is complete and re-utilization is negligible. Strontium released from litter comprises the entire flux of stream $\mathrm{Sr}$ export, which occurs exclusively as dissolved Sr. 


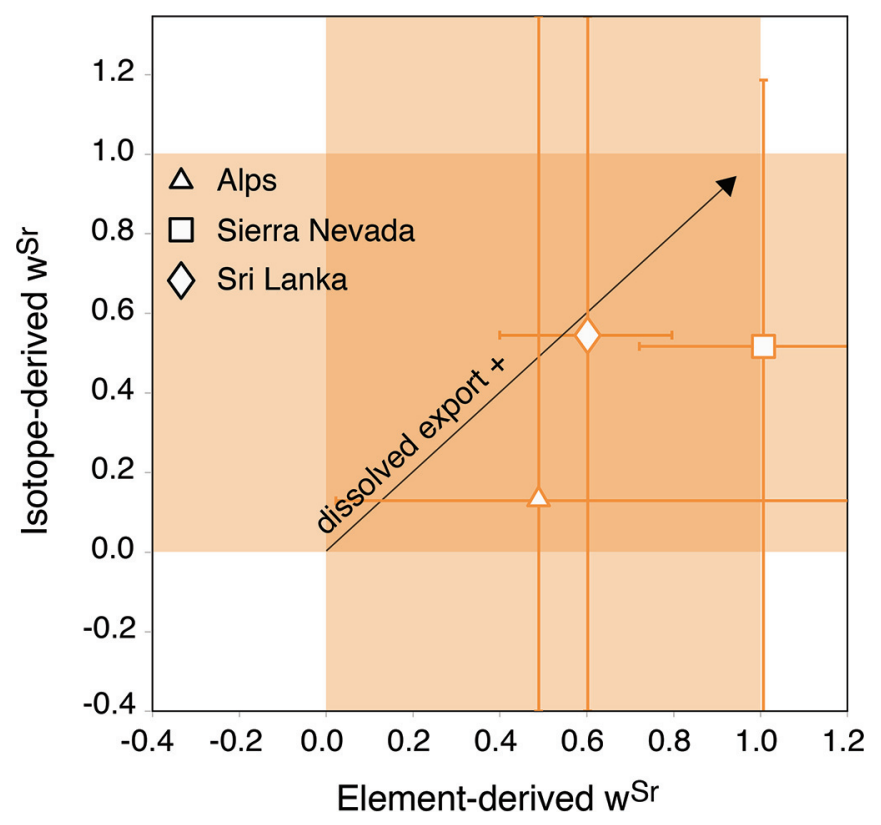

Fig. 8. Comparison between element-based (X-axis) and isotope-based (Y-axes) estimates of the relative export flux of dissolved $\mathrm{Sr} w^{S r}($ eqs $(8)$ and $(9))$. The areas shaded in orange denote the limits in flux allowed by the steady state model of Bouchez and others (2013).

- In Sri Lanka, not only do plants utilize all Sr released from regolith, but each atom of $\mathrm{Sr}$ is bio-utilized multiple times (typically 6 times) by release from plant litter before export to streams. However, a significant fraction of $\mathrm{Sr}$ in litter still remains refractory to re-dissolution. Thus export of $\mathrm{Sr}$ in organic debris dominates the stream export, dwarfing both dissolved Sr stream export and that eroded in primary minerals.

Whether $\mathrm{Sr}$ is exported in organic particles or is remobilised by dissolution from litter does not appear to depend on erosion rate nor residence time, a control that was identified for $\mathrm{Sr}$ export in the Chilean Coastal Cordillera (Oeser and von Blanckenburg 2020a). In the Alps, where grasslands were sampled, it is most likely that the steep slopes and an absence of canopy favor litter erosion through sheet wash and other surficial erosion processes, or, possibly, through grazing by the lifestock present at the site. In Sri Lanka, in contrast, a corollary of the low erosion rates is that litter-bound $\mathrm{Sr}$ is not efficiently removed by erosion. On the other hand, $\mathrm{Sr}$ is avaible for re-utilization by plants which can be related to the high litter quality typically observed for some tropical ecosystems (Hättenschwiler and others, 2011).

These effects are element-dependent, however. We note that efficient re-dissolution of $\mathrm{Mg}$ from litter in Sri Lanka was reported by Schuessler and others (2018) in the absence of its erosion in organic particles, while for Sierra Nevada Uhlig and others (2017) showed incomplete Mg re-dissolution from litter accompanied by its erosion in plant debris, unlike what we find for $\mathrm{Sr}$ in the present study. Although we have no means to pinpoint the reason for this difference between $\mathrm{Mg}$ and $\mathrm{Sr}$, it can be speculated that this difference is due to the "speciation" that might differ between $\mathrm{Sr}$ (for example located in oxalates; Hanger, 1979) and $\mathrm{Mg}$ in the plant (for example in chlorophyll; Maguire and Cowan, 2002). In addition, Sr is likely present mostly in leaf 


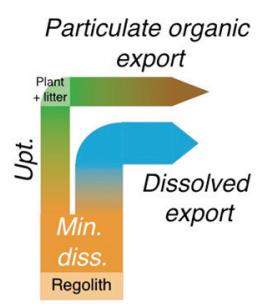

Alps

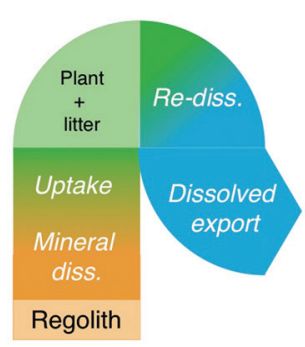

Sierra Nevada

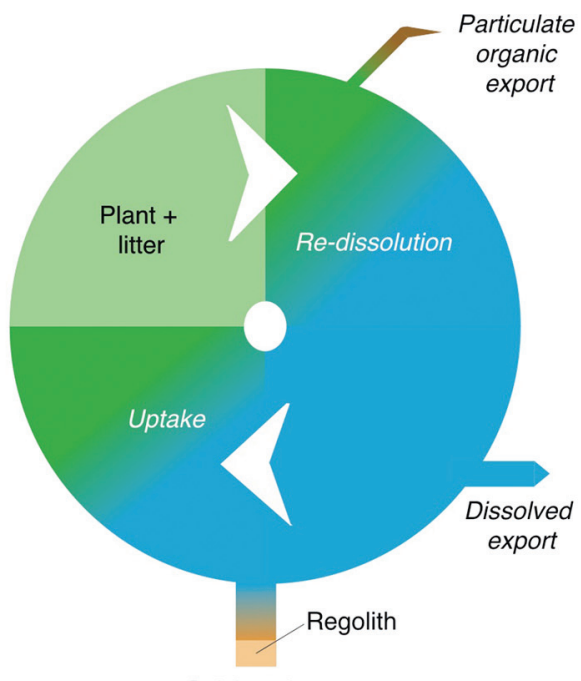

Sri Lanka

Fig. 9. Sketch of relative Sr fluxes between Critical Zone compartments along the erodosequence. The size of the arrows scales with the size of the fluxes. Fluxes in orange depict the regolith, in green the plant compartment (higher plants and litter), in blue the dissolved stream export and in brown the particulate organic export. Regular text denotes compartment names (regolith and plant plus litter) and text in italics denotes processes. Because the erosion does not impact isotope ratios and because the formation of secondary solids can be neglected, the stream export of minerals is not shown. The absence of a brown arrow for the Sierra Nevada site reflects the complete re-dissolution of Sr from litter at this site, whereas the circular shape for the Sri Lanka site reflects the efficient recycling of Sr from litter.

litter, whereas a substantial proportion of $\mathrm{Mg}$ may get eroded in tree trunks (Uhlig and others, 2017). Another picture still emerges for Si, where high fractions of $\mathrm{Si}$ in plant debris or biosilica are eroded $(20-40 \%)$, as suggested by both the values of $\operatorname{DEE}^{\mathrm{Si}}(c a .50 \%)$ and constraints from Ge/Si (Frings and others, 2021a, 2021b).

The high primary productivity at the Sri Lanka site is typical for tropical forests. The only way to maintain such a productive ecosystem in spite of sometimes total soluble element depletion is through the intensive recycling of rock-derived nutrients. Such strategy does not appear to be a requirement in fast eroding landscapes (Alps and Sierra Neveda), where weathering fluxes are sufficiently high to compensate for particulate (Alps) or dissolved (Sierra Nevada) Sr losses from the litter pool.

\section{CONCLUSIONS}

The main methodological finding of our study is:

(i) For an erodosequence, where fluxes are assumed to be at steady state, two entirely different means to determine elemental export fluxes provide internally consistent results: Sr stable isotope signatures on the one hand, and independent flux estimates from elemental $\mathrm{Sr}$ mass balance on the other hand.

These estimates show that:

(ii) Incorporation of Sr into secondary products of weathering (that is, through the formation of clays and oxides, or through adsorption onto mineral and organic surfaces) does not constitute a significant flux of $\mathrm{Sr}$ at the scale of the weathering zone, regardless of the erosion rate. Thus Sr fluxes from either elemental mass balance or Sr stable isotopes allow for the evaluation of pathways exclusively arising from primary mineral dissolution and biological cycling. 
(iii) At the site featuring the lowest denudation rate, secondary solids like oxides or clay minerals do host some $\mathrm{Sr}$, and these are enriched in the light $\mathrm{Sr}$ isotopes compared to $\mathrm{Sr}$ in solution. A first $\mathrm{Sr}$ stable isotope fractionation factor for formation of secondary solids derived thereof is $-0.32 \pm 0.13 \%$ (Sri Lanka). In contrast, Sr isotopes are not significantly fractionated when $\mathrm{Sr}$ is sorbed into the exchangeable pool from soil water.

(iv) The Sr stable isotope fractionation factor associated with biological uptake into plants ranges from $-0.34 \pm 0.23 \%$ (Sierra Nevada) to $-0.06 \pm 0.15$ (Sri Lanka). These differences might reflect a role of plant species-specific factors.

(v) Biological uptake of $\mathrm{Sr}$, followed either by release from litter to the soil solution or by litter erosion, acts as the major pathway of Sr in the Critical Zone. As a consequence, biologically cycled $\mathrm{Sr}$ dominates $\mathrm{Sr}$ dissolved stream export, while $\mathrm{Sr}$ bound to solid organic matter constitutes the predominant form of particulate Sr stream export.

Combined with other metal stable isotope tracers such as the Li or $\mathrm{Si}$ systems, $\mathrm{Sr}$ stable isotopes appear to offer a potentially powerful tool to disentangle the effects of biological processes from the overall cycling of elements in the Critical Zone.

\section{ACKNOWLEDGMENTS}

Jan Schuessler and Jutta Schlegel (once Bartel) are acknowledged for analytical support. This manuscript benefited from fruitful discussions with Jan Schuessler, Marcus Oelze, Patrick Frings, Jeannie Dixon, Tilak Hewawasam, and Kevin Norton. Andrew Jacobson, Ross Stevenson, and Associate Editor Daniel Ibarra are all thanked for constructive reviews that led us to improve the manuscript.

\section{APPENDIX A}

\section{Methods for Sequential Extractions from Saprolite and Soil Samples}

Sequential leaching was performed on selected saprolite and soil samples. The procedure (summarized in table A1) was adapted from previous protocols used in soil and river sediment studies (Tessier and others, 1979; Wittmann and others, 2012) and those used in studies of Sr isotopes in weathering systems (for example, Bullen and others, 1997; Pett-Ridge and others, 2009). Non-grinded sample splits $<2 \mathrm{~mm}$ (only samples from the corestone collected in the deep saprolite in Sri Lanka were crushed and ground) were first transferred to clean PP tubes, in which all extraction steps were carried out sequentially. For each extraction step, after immersion in the reagent, samples were centrifuged, the supernatant was pipetted out, and the settled material was flushed at least once with the same reagent or with water, and the supernatant pipetted out again. The two supernatants were combined and transferred into clean PP tubes. Samples were first immersed in Milli-Q water in order to retrieve the "watersoluble" phase, thought to reflect the composition acquired by infiltrating water upon contact with the regolith. Then, ammonium acetate $\left(\mathrm{NH}_{4} \mathrm{Ac}, 1 \mathrm{M}\right.$, buffered at $\left.\mathrm{pH} 7\right)$ was used to extract the "exchangeable" phase, followed by carbonate selective digestion using $1 \mathrm{M}$ acetic acid. Fe-Mn-(oxy) (hydr) oxides were then leached from the sample using hydroxylamine $\left(\mathrm{NH}_{2} \mathrm{OH} 1 \mathrm{M}\right.$ in $\left.\mathrm{HCl}\right)$. This procedure dissolved both amorphous and crystalline oxides. Organic material was then dissolved using a $\mathrm{HNO}_{3-}$ $\mathrm{H}_{2} \mathrm{O}_{2}-\mathrm{H}_{2} \mathrm{O}$ mixture. We note that this step has the potential to dissolve silicate material to some extent. From the residue, the clay-sized fraction was finally separated with a gentle centrifugation step resulting in the decantation of larger particles. The cut-off size was estimated to be around $2 \mu \mathrm{m}$, although we acknowledge that this estimate suffers from a considerable uncertainty. 
The major element composition of sequential leaches was measured by ICP-OES in $\mathrm{HNO}_{3} 0.3 \mathrm{M}$ after appropriate dilution, using calibration standards with a matrix matched with that of the extraction step when necessary $\left(\mathrm{NH}_{4} \mathrm{Ac}\right.$, acetic acid, or $\left.\mathrm{NH}_{2} \mathrm{OH}\right)$.

We note that the different fractions thus extracted are only operationally defined. In particular, the method we used to separate the clay-sized fraction (gentle centrifugation) most likely does not separate all clay material: while on the one hand the finegrained material in suspension after centrifugation might still contain very fine primary minerals, on the other hand clay minerals attached to coarser primary silicates, or aggregated with or without other material such as oxides, may have not beed contained in the clay-sized fraction.

The selectivity of this procedure can be assessed by the major element composition of the various leachates (Data Table E). Depending on the sample, the exchangeable fraction represented between 0.1 and $18.0 \%$ of the total budget for soluble elements, with usually higher contribution for alkali-earth elements $(\mathrm{Mg}, \mathrm{Ca}, \mathrm{Ba}, \mathrm{Sr})$ than for alkali elements $(\mathrm{Na}, \mathrm{K})$. Only marginal contributions $(<0.1 \%)$ of $\mathrm{Si}, \mathrm{Ti}, \mathrm{Al}$ and $\mathrm{Fe}$ were found in this fraction, but significant contribution of Mn (up to $3.5 \%$ ). In general, the elemental contribution of this fraction to the total budget was found to be higher in the Sri Lanka samples, in particular in soils samples, than in other samples. The "carbonate" fraction hosted a significant contribution of the $\mathrm{Mg}, \mathrm{Ca}, \mathrm{Ba}$, and $\mathrm{Mn}$ (and to a lesser extent $\mathrm{Fe}$ ) but $\mathrm{Sr}$ was not detectable in most of these leachates. The "oxihydroxide" fraction contained a large contribution of total Fe (3.9-26.2 \%), $\mathrm{Mn}(0.8-74 \%), \mathrm{Al}(1.6-9.9 \%)$, and $\mathrm{Mg}(0.4-21.7 \%)$, lesser amounts of $\mathrm{Ca}, \mathrm{Ba}$, and $\mathrm{Ti}$ and marginal contributions of $\mathrm{Na}, \mathrm{K}, \mathrm{Si}$, and $\mathrm{Sr}$ (up to $2.4 \%$ of total $\mathrm{Sr}$ ). The "clay" fraction contained a large contribution of total $\mathrm{Sr}, \mathrm{Ca}, \mathrm{K}$, and $\mathrm{Al}$ ( $\mathrm{Si}$ was not measurable in those leachates, as they were digested with HF), that is up to on the order of $10 \%$. The "clay" fraction represented a small contribution of the total elemental budgets in the Swiss Alps and Sierra Nevada total regolith, and even in the samples of upper saprolite and top soil of the Sri Lankan regolith.

\section{APPENDIX B}

\section{Methods for Strontium Separation and Stable Isotope Analysis}

Strontium was separated from the sample matrix using column chromatography based on $0.2 \mathrm{~mL}$ of Sr-SPEC resin (Eichrom), following a procedure adapted from that traditionally used for radiogenic Sr isotope analysis (Horwitz and others, 1992; Pin and Bassin, 1992). Aliquots of the elution fractions were systematically analyzed by ICP-OES to check for $100 \%$-yield and purity. Special care was taken to purify Sr from $\mathrm{Ca}$ and $\mathrm{Ba}$, the elution of which can show tailing and therefore can contaminate the Sr fraction and compromise the measurement of Sr stable isotopes by bracketing (Scher and others, 2014; Romaniello and others, 2015). If significant residual Ca and $\mathrm{Ba}$ were observed in the $\mathrm{Sr}$ elution fraction $(\mathrm{Ca} / \mathrm{Sr}$ or $\mathrm{Ba} / \mathrm{Sr}>1)$, which was in particular observed for organic-rich matrices such as found in topsoil or vegetation samples, the eluate was evaporated and processed again through the same Sr-SPEC column.

Sr isotope ratios were measured using a MC-ICP-MS Neptune (ThermoFischer, Bremen) at GFZ combined with Jet- and X-cones in static mode. An APEX-Q (ESI) desolvating unit and a PFA micronebulizer $\left(100 \mu \mathrm{L} \min ^{-1}\right)$ was employed as a sample introduction system. A sensitivity of $5 \mathrm{~V} \mathrm{ng}^{-1} \mathrm{~min}^{-1}$ was typically achieved for ${ }^{88} \mathrm{Sr}$. Measurement parameters and methods for data reduction for ${ }^{87} \mathrm{Sr} /{ }^{86} \mathrm{Sr}$ are discussed 
TABLE A1

Protocol for sequential extractions used in this study

\begin{tabular}{|c|c|c|c|c|c|}
\hline Fraction & Reagent & Time & Procedure & Recovery & Note \\
\hline Water-soluble & $\begin{array}{c}\text {-Milli-Q } \mathrm{H}_{2} \mathrm{O} \\
2 \mathrm{~mL}\end{array}$ & $30 \mathrm{~min}$ & $\begin{array}{l}\text { Ultrasonic } \\
\text { bath }\end{array}$ & $\begin{array}{c}\text { Centrifugation } 4,400 \mathrm{rpm} \\
10 \mathrm{~min}+\text { pipetting }\end{array}$ & $\begin{array}{c}\text { Centrifugation step is short } \\
\text { to avoid release from } \\
\text { minerals }\end{array}$ \\
\hline Exchangeable & $\begin{array}{c}-\mathrm{NH}_{4} \mathrm{Ac} 1 \mathrm{M} \\
(\mathrm{pH} \mathrm{7}) \\
4 \mathrm{~mL} \\
\end{array}$ & $1 \mathrm{~h}$ & $\begin{array}{l}\text { Ultrasonic } \\
\text { bath }\end{array}$ & $\begin{array}{c}\text { Centrifugation } 4,400 \mathrm{rpm} \\
10 \mathrm{~min}+\text { pipetting, repeat } \\
\text { with } 2 \mathrm{~mL} \mathrm{NH}_{4} \mathrm{Ac} \\
\end{array}$ & \\
\hline Carbonates & $\begin{array}{c}\text { - Acetic acid } \\
1 \mathrm{M} \\
4 \mathrm{~mL}\end{array}$ & $2 \mathrm{~h}$ & $\begin{array}{l}\text { Ultrasonic } \\
\text { bath }\left(50^{\circ} \mathrm{C}\right)\end{array}$ & $\begin{array}{l}\text { Centrifugation } 4,400 \mathrm{rpm} \\
10 \mathrm{~min}+\text { pipetting, repeat } \\
\text { with } 2 \mathrm{~mL} \text { MilliQ } \mathrm{H}_{2} \mathrm{O}\end{array}$ & $\begin{array}{l}\text { Followed by soaking the } \\
\text { residue in } 5 \mathrm{~mL} \mathrm{H}_{2} \mathrm{O} \\
\text { overnight in an ultrasonic } \\
\text { bath to disperse particles } \\
\text { (then decanted by } \\
\text { centrifugation for } 10 \mathrm{~min} \text { at } \\
4,400 \mathrm{rpm}+\text { pipetting) }\end{array}$ \\
\hline Oxides & $\begin{array}{c}-\mathrm{NH}_{2} \mathrm{OH} \\
1 \mathrm{M} \\
4 \mathrm{~mL} \\
\end{array}$ & $3.5 \mathrm{~h}$ & $\begin{array}{l}\text { Ultrasonic } \\
\text { bath }\left(80^{\circ} \mathrm{C}\right)\end{array}$ & $\begin{array}{c}\text { Centrifugation } 4,400 \mathrm{rpm} \\
10 \text { min + pipetting, repeat } \\
\text { with } 2 \mathrm{~mL} \text { MilliQ } \mathrm{H}_{2} \mathrm{O} \\
\end{array}$ & $\begin{array}{l}\text { Includes both crystalline } \\
\text { and amorphous oxidesispep? }\end{array}$ \\
\hline Organics & $\begin{array}{c}-\mathrm{H}_{2} \mathrm{O}_{2} \quad 30 \% \\
1.5 \mathrm{~mL} \\
-\mathrm{HNO}_{3} \quad 14 \mathrm{M} \\
2 \mathrm{~mL} \\
-\mathrm{MilliQ} \mathrm{H}_{2} \mathrm{O} \\
1.5 \mathrm{~mL}\end{array}$ & $2-12 h$ & $\begin{array}{l}\text { Transfer to } \\
\text { teflon vials }\end{array}$ & $\begin{array}{l}\text { Centrifugation } 4,400 \mathrm{rpm} \\
10 \mathrm{~min}+\text { pipetting, repeat } \\
\text { with } 2 \mathrm{~mL} \text { MilliQ } \mathrm{H}_{2} \mathrm{O}\end{array}$ & $\begin{array}{l}\text { Most likely contains } \\
\text { elements released from } \\
\text { silicate minerals, thus not } \\
\text { considered here }\end{array}$ \\
\hline Clays & $\begin{array}{l}\text { - MilliQ } \mathrm{H}_{2} \mathrm{O} \\
5 \mathrm{~mL}\end{array}$ & $2 \min$ & $\begin{array}{c}\text { Back in } \\
\text { centrifuge } \\
\text { tubes, } \\
\text { centrifugation } \\
500 \mathrm{rpm}\end{array}$ & $\begin{array}{c}\text { Pipetting and drying } \\
\text { followed by } \mathrm{HF}-\mathrm{HNO}_{3} \\
\text { digestion }\end{array}$ & $\begin{array}{l}\text { Centrifugation is used here } \\
\text { to settle silt- and sand- } \\
\text { sized particles }\end{array}$ \\
\hline
\end{tabular}

elsewhere (Hewawasam and others, 2013; von Blanckenburg and others, 2021). For ${ }^{88} \mathrm{Sr} /{ }^{86} \mathrm{Sr}$ ratios, instrumental mass fractionation was corrected by standard-samplestandard bracketing (Fietzke and Eisenauer, 2006; Rüggeberg and others, 2008; Ma and others, 2013). This method is more demanding in terms of Sr recovery yield during chemical purification, solution purity, and instrument stability during measurements compared to the double-spike technique (Krabbenhoft and others, 2009; Shalev and others, 2013; Neymark and others, 2014). However, the approach does not require the calibration of a spike solution and allows for the measurement of all isotope ratios of interest $\left({ }^{88} \mathrm{Sr} /{ }^{86} \mathrm{Sr}\right.$ and $\left.{ }^{87} \mathrm{Sr} /{ }^{86} \mathrm{Sr}\right)$ in a single run. Tests were made using the Zr-doping technique (Ohno and Hirata, 2007; Yang and others, 2008; Krachmaninov and others, 2012), but these tests did not yield satisfactory results. It was ensured that the drift of instrumental fractionation was as small as possible between a sample and its two bracketing standards. To this end, short integration times were used, such that each standard-sample-standard sequence was achieved within a few minutes. If the drift between two standards exceeded $0.1 \%$ in ${ }^{88} \mathrm{Sr} /{ }^{86} \mathrm{Sr}$, sample results between these two standards were discarded. Intensity matching between samples and standards was systematically checked to be within $\pm 20 \%$. Stable Sr isotope ratios were finally reported as:

$$
\delta^{88} \operatorname{Sr}[\% \mathrm{o}]=\left(\frac{\left({ }^{88} S r /{ }^{86} S r\right)_{\text {sample }}}{\left({ }^{88} S r /{ }^{86} S r\right)_{S R M 987}}-1\right)
$$


where SRM987 is a solution made from the international isotope $\mathrm{Sr}$ carbonate standard NBS SRM987. Repeated runs of the SRM987 solution over several years served to check the accuracy and repeatability of the ${ }^{87} \mathrm{Sr} /{ }^{86} \mathrm{Sr}$ mass spectrometric measurements, but also the stability of the drift in instrumental mass fractionation during sessions.

Over three years of measurements and a dozen of measurement sessions, a pure Sr solution (ICP standard Certipur) was regularly measured by bracketing, and gave $\delta^{88} \mathrm{Sr}=-0.019 \pm 0.098 \%$ (2 standard deviation $\left.=2 \mathrm{SD}, \mathrm{n}=154\right)$ and ${ }^{87} \mathrm{Sr} /{ }^{86} \mathrm{Sr}=$ $0.708600 \pm 0.000069(2 \mathrm{SD}, \mathrm{n}=162)$. This uncertainty provides an estimate of the instrument stability between sessions. However, it does not reflect the uncertainty on the mean value of the measurements, which is provided in this study by the $95 \%$ confidence intervals of repeated sample measurements (hereafter referred to as C.I., calculated as $t_{n-1} \times$ S.D. $/ \sqrt{n}$, with $n$ being the number of measurements and $t_{n-1}$ Student's factor for $n-1$ degrees of freedom). When several chemical separations were made from the same sample, all measurements were combined to calculate the C.I. For the Certipur solution, the C.I. on $\delta^{88} \mathrm{Sr}$ is $0.016 \%$ (meaning that our best estimate for this value is $-0.019 \pm 0.008 \%$ ) and the C.I. on ${ }^{87} \mathrm{Sr} /{ }^{86} \mathrm{Sr}$ is 0.000011 (best estimate $0.708600 \pm 0.000006$ )

To ascertain accuracy of our measurements, and given the scarcity of well-constrained $\delta^{88} \mathrm{Sr}$ values of natural material in the literature, we processed in-house synthetic standards, made from a Certipur ICP standard Sr solution and other mono-elemental solutions, through the separation procedure and measured their isotope ratios as if they were samples. The composition of these synthetic standards is provided in table A2. Given the numbers provided above for the Certipur solution, accurate measurements of these synthetic standards should yield $\delta^{88} \mathrm{Sr}=$ $-0.019 \pm 0.008 \%{ }^{87} \mathrm{Sr} /{ }^{86} \mathrm{Sr}=0.708600 \pm 0.000006$. Results of measurements of $\delta^{88} \mathrm{Sr}$ and ${ }^{87} \mathrm{Sr} /{ }^{86} \mathrm{Sr}$ are provided in table A3 and show that within uncertainty, our separation and measurement method produces no shift in $\delta^{88} \mathrm{Sr}$ shift and only a minor upward shift in ${ }^{87} \mathrm{Sr} /{ }^{86} \mathrm{Sr}$ values which might be due to the presence of minute amounts of $\mathrm{Sr}$ in the mono-elemental solutions used to produce these synthetic standards. To further check the accuracy of our method, we processed several reference materials for which $\delta^{88} \mathrm{Sr}$ data exist in the literature, again yielding a good agreement between our own measurements and previously reported values (table A3). We also processed and measured reference materials for which, to our knowledge, no available $\delta^{88} \mathrm{Sr}$ data exist, but served as tests for the repeatability of our measurements and provide a benchmark for future Sr isotope measurements (table A3).

APPENDIX C

\section{Non-Silicate Strontium Contribution to The Critical Zone}

Strontium can be delivered to weathering profiles not only by conversion of rock to regolith, but also through atmospheric inputs at the top of the regolith. This effect is likely to be the most prominent for low-erosion settings where the rock supply is the slowest (Jssacobson and others, 2002; Kurtz and others, 2001). Quantifying Sr external inputs to weathering profiles might be of importance for $\delta^{88} \mathrm{Sr}$, as for example carbonate minerals sometimes contained in dust will have a lower $\delta^{88} \mathrm{Sr}$ composition than that of silicate minerals (the average $\delta^{88} \mathrm{Sr}$ value of Phanerozoic carbonates being $0.16 \%$; Vollstaedt and others, 2014). Conversely, wet atmospheric inputs have a $\delta^{88} \mathrm{Sr}$ composition close to that of seawater, heavier than that of most minerals (Pearce and others, 2015a). To quantify carbonate-derived inputs for the three sites of the erodosequence, we use results from Sr source apportionment based on the 
"radiogenic" Sr isotope ratio, as reported by von Blanckenburg and others (2021). As discussed by Uhlig et al. (2017) and von Blanckenburg (2021), no particular correction with respect to atmospheric inputs is needed for the Sierra Nevada site. Therefore, in the following we discuss the role of this contribution for the Alps and Sri Lanka sites only.

For the Alps von Blanckenburg and others (2021) show that although the sampled regolith profiles are not affected by dust inputs, a measurable contribution of a carbonate end member to the dissolved load is apparent in the streams samples nevertheless. Radiogenic Sr isotope ratios show that the fraction of silicate-derived dissolved Sr ranges from 0.42 in streams draining the Goms profile hillslope to 0.05 in the larger Rhone River (von Blanckenburg and others, 2021). Together with a $\sim 10 \%$ correction on the $\mathrm{Na}$ dissolved load from wet deposition contributions (von Blanckenburg and others, 2021), a silicate-derived $(\mathrm{Sr} / \mathrm{Na})_{\text {diss }}$ ratio can be calculated (Data Table A2), with values of $1.29 \pm 0.95$ (1SD) for Goms stream water. This is the ratio we use in equations (4) and (8). In principle the inferred $\mathrm{Sr}$ contribution from the silicate end member values could be used to estimate the $\delta^{88} \mathrm{Sr}$ value of the silicate end member, provided that the $\delta^{88} \mathrm{Sr}$ of the carbonate end member is known. However, in the case of the Alps the value of this end member is difficult to constrain. A mean of $0.16 \%$ is reported for Phanerozoic carbonates by Vollstaedt and others (2014), but with a wide range of variations. Therefore, given the uncertainty that would be associated with such a correction on the dissolved $\delta^{88} \mathrm{Sr}$ values of the water samples in the Alps (especially for those samples with very low values contribution of the silicate end member to dissolved $\mathrm{Sr}$ ) we did not attempt any correction. Unfortunately, this introsduces potential bias into the calculations made using equations (1), (2), and (9) for the Alps.

For Sri Lanka Hewawasam and others (2013) and Schuessler and others (2018) show dust input to be important for major elements and for $\mathrm{Sr}$ for the Hakgala profile. In terms of solid material, such contribution is apparent from the much lower ${ }^{87} \mathrm{Sr} /{ }^{86} \mathrm{Sr}$ ratios in topsoil and plant samples than in the underlying weathering profile (fig. 3). Because in Sri Lanka - unlike in the Alps - dust is deposited onto the regolith (for example, fig. 3) and thus contributes to Sr cycling by plants, the "raw" (that is, not corrected for non-silicate contribution) $(\mathrm{Sr} / \mathrm{Na})_{\text {diss }}$ and dissolved $\delta^{88} \mathrm{Sr}$ values can be used in equations (4) and (8) (von Blanckenburg and others, 2021).

However, in order to provide a value for $\delta_{\text {parent }}^{S r}$ that takes into account dust input, it is required to estimate the relative $\mathrm{Sr}$ contribution to the regolith profile of rock weathering ansd dry deposition. The contribution of dust-derived Sr to the Critical Zone in Sri Lanka can be estimated from its contribution to stream dissolved Sr (von Blanckenburg and others, 2021). This estimate yields fractional contributions of the silicate $\mathrm{Sr}$ end member between 0.08 and 0.16 for the small creeks around the regolith

\section{TABLE A2}

Composition of the in-house synthetic samples produced to check accuracy of Sr isotope measurements. The X/Sr ratio of the solutions made are given, as well as the typical $\mathrm{Sr}$ amount that was loaded onto the Sr-SPEC columns for each in-house synthetic standard

\begin{tabular}{|c|c|c|c|c|c|c|c|c|c|c|c|c|c|c|c|c|c|}
\hline & & & & & & & & $X / S r$ & ratio & & & & & & & & $S r$ \\
\hline $\begin{array}{l}\text { Synth. } \\
\text { sample }\end{array}$ & $\mathrm{Si}$ & $\mathrm{Na}$ & $\bar{~} \bar{K}$ & $M g$ & $\mathrm{Ca}$ & $A l$ & $\mathrm{Fe}$ & $T i$ & $B a$ & $\mathrm{Cr}$ & $M n$ & $\mathrm{Co}$ & $\mathrm{Ni}$ & $\mathrm{Cu}$ & $Z n$ & $B$ & {$[\mu g]$} \\
\hline RW1 & 100 & 100 & 50 & 25 & 100 & & & & & & & & & & & & 1.0 \\
\hline RM3 & 1500 & 50 & 67 & 50 & 50 & 400 & 250 & 25 & 2.5 & 0.3 & 4.2 & 0.3 & 0.3 & 0.3 & 1.0 & & 0.2 \\
\hline Plant3 & 160 & 1 & 640 & 120 & 600 & 12 & 4.0 & & 2.0 & & 2.0 & & & & 0.4 & 1.0 & 0.2 \\
\hline
\end{tabular}


TABLE A3

Summary of ${ }^{87} \mathrm{Sr} /{ }^{86} \mathrm{Sr}$ and $\delta^{88} \mathrm{Sr}$ measurement statistics for refence materials and in-house synthetic samples.

\begin{tabular}{|c|c|c|c|c|c|c|c|c|c|c|c|}
\hline & & \multicolumn{5}{|c|}{${ }^{87} \mathrm{Sr} /{ }^{86} \mathrm{Sr}$} & \multicolumn{5}{|c|}{$\delta^{88} \mathrm{Sr}$} \\
\hline & nc & Mean & $\begin{array}{r}\text { 2SD } \\
{\left[10^{-6}\right]}\end{array}$ & $\begin{array}{c}22 \mathrm{SE}_{\mathrm{t}} \\
{\left[10^{-6}\right]}\end{array}$ & $\mathrm{n}_{\mathrm{s}}$ & $\mathrm{n}_{\mathrm{m}}$ & $\begin{array}{c}\text { Mean } \\
{[\% \circ]}\end{array}$ & $\begin{array}{l}\text { 2SD } \\
{[\%]}\end{array}$ & $\begin{array}{l}2 \mathrm{SE}_{\mathrm{t}} \\
{[\% \mathrm{c}]}\end{array}$ & $\mathrm{n}_{\mathrm{s}}$ & $\mathrm{n}_{\mathrm{m}}$ \\
\hline \multicolumn{12}{|c|}{ Reference materials } \\
\hline SLRS-5a & 5 & 0.711047 & 42 & 8 & 5 & 29 & 0.336 & 0.144 & 0.033 & 5 & 21 \\
\hline SRM1640a & 3 & 0.708867 & 30 & 7 & 4 & 21 & 0.139 & 0.080 & 0.019 & 4 & 19 \\
\hline SRM1515 & 4 & 0.713541 & 150 & 32 & 3 & 21 & 0.241 & 0.046 & 0.010 & 3 & 23 \\
\hline SRM2709ab & 4 & 0.708133 & 70 & 14 & 4 & 28 & 0.245 & 0.116 & 0.027 & 3 & 20 \\
\hline BHVO-1c & 2 & 0.703479 & 32 & 17 & 1 & 6 & 0.266 & 0.026 & 0.016 & 1 & 5 \\
\hline JLs-1d & 2 & 0.707887 & 34 & 18 & 1 & 6 & 0.336 & 0.110 & 0.068 & 1 & 5 \\
\hline JS1-1 & 3 & 0.711836 & 44 & 17 & 1 & 9 & -0.199 & 0.100 & 0.042 & 1 & 8 \\
\hline \multicolumn{12}{|c|}{ In-house synthetic samples } \\
\hline RW1 & 3 & 0.708664 & 96 & 18 & 5 & 29 & -0.034 & 0.096 & 0.028 & 3 & 14 \\
\hline RM3 & 4 & 0.708629 & 190 & 47 & 3 & 18 & 0.031 & 0.098 & 0.037 & 2 & 9 \\
\hline Plant3 & 3 & 0.708662 & 100 & 25 & 2 & 18 & 0.007 & 0.082 & 0.017 & 2 & 24 \\
\hline Certipur & NA & 0.708600 & 69 & 11 & 8 & 162 & -0.019 & 0.098 & 0.015 & 7 & 154 \\
\hline
\end{tabular}

$\mathrm{n}_{\mathrm{c}}, \mathrm{n}_{\mathrm{s}}$, and $\mathrm{n}_{\mathrm{m}}$ refer to the number of runs of chromatographic separation, number of MC-ICP-MS sessions, and number of individual measurements that were performed for each solution. 2SD is twice the standard deviation on all measurements and $2 \mathrm{SE}_{\mathrm{t}}$ is the corresponding confidence interval at $95 \%$, calculated with Student's law at $\mathrm{n}_{\mathrm{m}}$ degrees of freedom. $\mathrm{n}_{\mathrm{m}}$ can differ between between between ${ }^{87} \mathrm{Sr} /{ }^{86} \mathrm{Sr}$ and $\delta^{88} \mathrm{Sr}$ because (1) some ${ }^{87} \mathrm{Sr} /{ }^{86} \mathrm{Sr}$ data were discarded when $\mathrm{Kr}$ interference on mass 86 was too high, and (2) some $\delta^{88} \mathrm{Sr}$ data were discarded when the drift in instrumental mass fractionation was higher than 0.10 (in $\delta^{88} \mathrm{Sr}$ unit) between two consecutive standards. The composition of the in-house synthetic standards is given in Table A2. The results of ${ }^{87} \mathrm{Sr} /{ }^{86} \mathrm{Sr}$ and $\delta^{88} \mathrm{Sr}$ measurements of the "Certipur" solution (mono-elemental Sr ICP standard) used to supply Sr to these in-house synthetic samples is given for reference.

${ }^{a}$ Krabbenhöft and others (2010) report a $\delta^{88} \mathrm{Sr}$ value of $0.34 \pm 0.03 \%$ (2SE) for the St-Lawrence river, from which the reference material SLRS-5 was sampled.

${ }^{\mathrm{b}}$ Brazier and others $(2020)$ report a $\delta^{88} \mathrm{Sr}$ value of $0.162 \pm 0.019 \%(2 \mathrm{SD}, \mathrm{n}=69)$ and a ${ }^{87} \mathrm{Sr} /{ }^{86} \mathrm{Sr}$ ratio of $0.70814 \pm 0.00002(2 \mathrm{SD}, \mathrm{n}=25)$.

${ }^{\mathrm{c}}$ Charlier and others (2012) report a $\delta^{88} \mathrm{Sr}$ value of $0.29 \pm 0.08 \%$ and $0.32 \pm 0.11 \%$ (2SE), Wei and others report a ${ }^{87} \mathrm{Sr}{ }^{86} \mathrm{Sr}$ ratio of $0.703484 \pm 0.000021(2 \mathrm{SD}, \mathrm{n}=8)$, and Andrews and others (2016) report a $\delta^{88} \mathrm{Sr}$ value of $0.267 \pm 0.008 \%(2 \mathrm{SE}, \mathrm{n}=12)$ for BHVO- 1 .

d Ohno and Hirata (2007) report a $\delta{ }^{88} \mathrm{Sr}$ value of $0.26 \pm 0.04 \%$ (2SD) for JLs-1, and Brazier and others $(2020)$ report $\delta^{88} \mathrm{Sr}$ values of $0.257 \pm 0.019 \%(2 \mathrm{SD}, \mathrm{n}=69)$ and $0.225 \pm 0.019 \%(2 \mathrm{SD}, \mathrm{n}=69)$ depending on the digestion protocol.

profile (von Blanckenburg and others, 2021). This means that carbonate dust contributes to around $85 \%$ of the Sr supply to the regolith profile in Sri Lanka, and thus that the $R P^{S r}$ value provided by von Blanckenburg and others (2021) derived only from silicate weathering in the saprolite has to be multiplied by around 7 to take carbonate input into account. Using these fractional contributions together with the $\delta^{88}$ Sr values of bedrock $\left(0.24 \pm 0.03\right.$, excluding one sample with lower $\delta^{88} \mathrm{Sr}$ value; Data Table SL1) and top soil (see above) we estimate that $\delta_{\text {parent }}^{S r}=0.09 \pm 0.03$. This value is used for estimates of $\varepsilon_{\text {prec }}^{S r}\left(\right.$ eq 1), $\varepsilon_{u p t}^{S r}$ (eq 2), $e_{o r g}^{S r}$ (eq 5), and $w^{S r}$ (eq 9). However, this estimate of $\delta_{\text {parent }}^{S r}$ may be biased if either dust Sr or silicate Sr solubilisation is incomplete. The fact that Sr release from the Sri Lanka local bedrock is complete is shown by the the $\tau_{\mathrm{Sr}}$ values of -1 in the upper saprolite (fig. 2). However, dissolution of carbonate dust in top soil is not complete (fig. 2). Nevertheless, because the difference between the $\delta^{88} \mathrm{Sr}$ values of bedrock and carbonate dust is minor, this assumption does not strongly affect our estimate of $\delta_{\text {parent }}^{S r}$. 


\section{REFERENCES}

Åberg, G., Jacks, G., Wickman, T., and Hamilton, P. J., 1990, Strontium isotopes in trees as an indicator for calcium availability: Catena, v. 17, n. 1, p. 1-11, https://doi.org/10.1016/0341-8162(90)90011-2

Al-Khatib, M., and Eisenhauer, A., 2016, Calcium and strontium isotope fractionation during precipitation from aqueous solutions as a function of temperature and reaction rate: II. Aragonite: Geochimica et Cosmochimica Acta, v. 209, p. 320-342, https://doi.org/10.1016/j.gca.2017.04.012

Amsellem, E., Moynier, F., Day, J. M. D., Moreira, M., Puchtel, I. S., and Teng, F.-Z., 2018, The stable strontium isotopic composition of ocean island basalts, mid-ocean ridge basalts, and komatiites: Chemical Geology, v. 483, p. 595-602, https://doi.org/10.1016/j.chemgeo.2018.03.030

Anderson, S. P., von Blanckenburg, F., and White, A. F, 2007, Physical and chemical controls on the Critical Zone: Elements, v. 3, n. 5, p. 315-319, https://doi.org/10.2113/gselements.3.5.315

Andrews, M. G., and Jacobson, A. D., 2017, The radiogenic and stable Sr isotope geochemistry of basalt weathering in Iceland: Role of hydrothermal calcite and implications for long-term climate regulation: Geochimica et Cosmochimica Acta, v. 215, p. 247-262, https://doi.org/10.1016/j.gca.2017.08.012

Andrews, M. G., and Jacobson, A. D., 2018, Controls on the solute geochemistry of subglacial discharge from the Russell Glacier, Greenland Ice Sheet determined by radiogenic and stable Sr isotope ratios: Geochimica et Cosmochimica Acta, v. 239, p. 312-329, https://doi.org/10.1016/j.gca.2018.08.004

Andrews, M. G., Jacobson, A. D., Lehn, G. O., Horton, T. W., and Craw, D., 2016, Radiogenic and stable Sr isotope ratios $\left({ }^{87} \mathrm{Sr} /{ }^{86} \mathrm{Sr}, \delta^{88 / 86} \mathrm{Sr}\right)$ as tracers of riverine cation sources and biogeochemical cycling in the Milford Sound region of Fiordland, New Zealand: Geochimica et Cosmochimica Acta, v. 173, p. 284-303, https://doi.org/10.1016/j.gca.2015.10.005

Bain, D. C., and Bacon, J. R., 1994, Strontium isotopes as indicators of mineral weathering in catchments: Catena, v. 22, p. 201-214, https://doi.org/10.1016/0341-8162(94)90002-7

Baronas, J. J, Torres, M. A., West, A. J., Rouxel, O., Georg, B., Bouchez, J., Gaillardet, J., and Hammond, D. E., 2018, Ge and $\mathrm{Si}$ isotope signatures in rivers: A quantitative multi-proxy approach: Earth and Planetary Science Letters, v. 503, p. 194-215, https://doi.org/10.1016/j.epsl.2018.09.022

Baronas, J. J., West, A. J., Burton, K. W., Hammond, D. E., Opfergelt, S., von Strandmann, P. A. P., James, R. H., and Rouxel, O. J., 2020, Ge and Si isotope behavior during intense tropical weathering and ecosystem cycling: Global Biogeochemical Cycles, v. 34, n.8, https:/ /doi.org/10.1029/2019GB006522

Behrens, R., Bouchez, J., Schuessler, J. A., Dultz, S., Hewawasam, T., and von Blanckenburg, F., 2015, Mineralogical transformations set slow weathering rates in low-porosity metamorphic bedrock on mountain slopes in a tropical climate: Geochimica et Cosmochimica Acta, v. 411, p. 283-298, https:// doi.org/10.1016/j.chemgeo.2015.07.008

Blechschmidt, I., and Vomvoris, S., 2015, The fourth decade of underground research at the Grimsel Test Site - What we have learned and where we go from here: Phoenix, Arizona, WMSYM WM2015 Conference, Achieving Results through Technology and Innovation on a Global Scale, March 15-19, 2015.

Blum, J. D., and Erel, Y., 1997, Rb-Sr isotope systematics of a granitic soil chronosequence: The importance of biotite weathering: Geochimica et Cosmochimica Acta, v. 61, n. 15, p. 3193-3204, https://doi.org/ 10.1016/S0016-7037(97)00148-8

Böhm, F., Eisenhauer, A., Tang, J., Dietzel, M., Krabbenhöft, A., Kisakürek, B., and Horn, C., 2012, Strontium isotope fractionation of planktic foraminifera and inorganic calcite: Geochimica et Cosmochimica Acta, v. 93, p. 300-314, https://doi.org/10.1016/j.gca.2012.04.038

Bolou-Bi, E. B., Poszwa, A., Leyval, C., and Vigier, N., 2010, Experimental determination of magnesium isotope fractionation during higher plant growth: Geochimica et Cosmochimica Acta, v. 74, n. 9, p. 25232537, https://doi.org/10.1016/j.gca.2010.02.010

Bouchez, J., and von Blanckenburg, F., 2021, Geochemical and strontium isotope data on Critical Zone compartments along a global soil erodosequence: GFZ Data Publication services, https://doi.org/10 .5880 /fidgeo.2021.026

Bouchez, J., von Blanckenburg, F., and Schuessler, J. A., 2013, Modeling novel stable isotope ratios in the weathering zone: American Journal of Science, v. 313, n. 4, p. 267-308, https://doi.org/10.2475/04 .2013 .01

Brazier, J.-M., Schmitt, A.-D., Pelt, É.j Lemarchand, D., Gangloff, S., Tacail, T., and Balter, V., 2020, Determination of radiogenic ${ }^{87} \mathrm{Sr} /{ }^{86} \mathrm{Sr}$ and stable $\delta^{88}{ }^{86} \mathrm{Sr}_{\mathrm{SRM} 987}$ isotope values of thirteen mineral, vegetal and animal reference materials by DS-TIMS: Geostandards and Geoanalytical Research, v. 44, n. 2, p. 331-348, https://doi.org/10.1111/ggr.12308

Bullen, T. D., and Bailey, S. W., 2005, Identifying calcium sources at an acid deposition-impacted spruce forest: A strontium isotope, alkaline earth element multi-tracer approach: Biogeochemistry, v. 74, p. 6399, https://doi.org/10.1007/s10533-004-2619-z

Bullen, T. D., and Chadwick, O. A., 2016, Ca, Sr and Ba stable isotopes reveal the fate of soil nutrients along a tropical climosequence in Hawaii: Chemical Geology, v. 422, p. 25-45, https://doi.org/10.1016/j .chemgeo.2015.12.008

Bullen, T. D., and Eisenhauer, A., 2009, Metal stable isotopes in low-temperature systems: A primer: Elements, v. 5, n. 6, p. 349-352, https://doi.org/10.2113/gselements.5.6.349

Bullen, T. D., White, A. F., Blum, A., Harden, J., and Schulz, M., 1997, Chemical weathering of a soil chronosequence on granitoid alluvium: II. Mineralogic and isotopic constraints on the behavior of strontium: Geochimica et Cosmochimica Acta, v. 61, n. 2, p. 291-306, https://doi.org/10.1016/S00167037(96) 00344-4

Burger, A., and Lichtscheidl, I., 2019, Strontium in the environment: Review about reactions of plants towards stable and radioactive strontium isotopes: Science of the Total Environment, v. 653, p. 14581512, https://doi.org/10.1016/j.scitotenv.2018.10.312 
Chadwick, O. A., Derry, L. A., Vitousek, P. M., Huebert, B. J., and Hedin, L. O., 1999, Changing sources of nutrients during four million years of ecosystem development: Nature, v. 397, p. 491-497, https://doi .org/10.1038/17276

Chao, H.-C., You, C.-F., Liu, H.-C., and Chung, C.-H., 2015, Evidence for stable Sr isotope fractionation by silicate weathering in a small sedimentary watershed in southwestern Taiwan: Geochimica et Cosmochimica Acta, v. 165, p. 324-341, https://doi.org/10.1016/j.gca.2015.06.006

Charbonnier, Q., Bouchez, J., Gaillardet, J., and Gayer, É., 2020, Barium stable isotopes as a fingerprint of biological cycling in the Amazon River Basin: Biogeosciences, v. 17, p. 5989-6015, https://doi.org/10 $.5194 /$ bg-17-5989-2020

Charlier, B. L. A., Nowell, G. M., Parkinson, I. J., Kelley, S. P., Pearson, D. G., and Burton, K. W., 2012, High temperature strontium stable isotope behaviour in the early solar system and planetary bodies: Earth and Planetary Science Letters, v. 329-330, p. 31-40 https://doi.org/10.1016/j.epsl.2012.02.008

Clow, D. W., Mast, M. A., Bullen, T. D., and Turk, J. T., 1997, Strontium 87/strontium 86 as a tracer of mineral weathering reactions and calcium sources in an alpine/subalpine watershed, Loch Vale, Colorado: Water Resources Research, v. 33, n. 6, p. 1335-1351, https://doi.org/10.1029/97WR00856

Dahlgren, R. A., Saigusa, M., and Ugolini, F. C., 2004, Nature, properties and management of volcanic soils: Advances in Agronomy, v. 82, p. 113-182, https://doi.org/10.1016/S0065-2113(03)82003-5

Dasch, A. A., Blum, J. D., Eagar, C., Fahey, T. J., Driscoll, C. T., and Siccama, T. G., 2006, The relative uptake of $\mathrm{Ca}$ and $\mathrm{Sr}$ into tree foliage using a whole-watershed calcium addition: Biogeochemistry, v. 80, n. 1, p. 21-41, https://doi.org/10.1007/s10533-005-6008-z

de Souza, G., Reynolds, B. C., Kiczka, M., and Bourdon, B., 2010, Evidence for mass-dependent isotopic fractionation of strontium in a glaciated granitic watershed: Geochimica et Cosmochimica Acta, v. 74, n. 9, p. 2596-2614, https://doi.org/10.1016/j.gca.2010.02.012

Dellinger, M., Gaillardet, J., Bouchez, J., Calmels, D., Louvat, P., Dosseto, A., Gorge, C., Alanoca, L., and Maurice, L., 2015, Riverine $\mathrm{Li}$ isotope fractionation in the Amazon River basin controlled by the weathering regimes: Geochimica et Cosmochimica Acta, v. 164, p. 71-93, https://doi.org/10.1016/j.gca .2015 .04 .042

Dellinger, M., Bouchez, J., Gaillardet, J., Faure, L., and Moureau, J., 2017, Tracing weathering regimes using the lithium isotope composition of detrital sediments, Geology, v. 45, n. 5, p. 411-414, https:// doi.org/10.1130/G38671.1

Dixon, J. L., Heimsath, A. M., and Amundson, R., 2009, The critical role of climate and saprolite weathering in landscape evolution: Earth Surface Processes and Landforms, v. 34, n. 11, p. 1507-1521, https://doi .org/10.1002/esp.1836

Dixon, J. L., Hartshorn, A. S., Heimsath, A. M., DiBiase, R. A., and Whipple, K. X., 2012, Chemical weathering response to tectonic forcing: A soils perspective from the San Gabriel Mountains, California: Earth and Planetary Science Letters, v. 323-324, p. 40-49, https://doi.org/10.1016/j.epsl.2012.01.010

Drouet, T., Herbauts, K., and Demaiffe, D., 2007, Change of the origin of calcium in forest ecosystems in the twentieth century highlighted by natural Sr isotopes: Terrestrial Ecology, p. 333-343, https://doi .org/10.1016/S1936-7961(07)01021-4

Druhan, J. L., and Winnick, M. J., 2019, Reactive transport of stable isotopes: Elements, v. 15, n. 2, p. $107-$ 110, https://doi.org/10.2138/gselements.15.2.107

Faure, G., and Powell, J. L., 1972, Strontium isotope geology: New York, Springer-Verlag, 197 p., https:// doi.org/10.1007/978-3-642-65367-4

Ferrier, K. L., and Kirchner, J. W., 2008, Effects of physical erosion on chemical denudation rates: A numerical modeling study of soil-mantled hillslopes: Earth and Planetary Science Letters, v. 272, n. 3-4, p. 591-599, https://doi.org/10.1016/j.epsl.2008.05.024

Fietzke, J., and Eisenhauer, A., 2006, Determination of temperature-dependent stable strontium isotope $\left({ }^{88} \mathrm{Sr} /{ }^{86} \mathrm{Sr}\right)$ fractionation via bracketing standard MC-ICP-MS: Geochemistry, Geophysics, Geosystems, v. 7, n. 8, GC1243, https://doi.org/10.1029/2006GC001243

Fontorbe, G., Frings, P. J., De La Rocha, C., Hendry, K. R., and Conley., D. J., 2020, Constraints on Earth System functioning at the Paleocene-Eocene Thermal Maximum from the marine silicon cycle: Paleoceanography and Paleoclimatology, v. 35, n. 5, https://doi.org/10.1029/2020PA003873

Frings, P. J., Clymans, W., Fontorbe, G., De La Rocha, C., and Conley, D. J., 2016, The continental Si cycle and its impact on the ocean $\mathrm{Si}$ isotope budget: Chemical Geology, v. 425, p. 12-36, https://doi.org/10 $.1016 /$ j.chemgeo.2016.01.020

Frings, P. J., Schubring, F., Oelze, M., and von Blanckenburg, F., 2021a, Quantifying biotic and abiotic Si fluxes in the Critical Zone with $\mathrm{Ge} / \mathrm{Si}$ ratios along a gradient of erosion rates: American Journal of Science, v. 321, n. 8, p. 1204-1245, https://doi.org/10.24.75/08.2021.03

Frings, F., Oelze, M., Schubring, F., Frick, D. A., and von Blanckenburg, F., 2021b, Interpreting silicon isotopes in the Critical Zone: American Journal of Science, v. 321, n. 8, p. 1164-1203, https://doi.org/10 $.24 .75 / 08.2021 .02$

Gaillardet, J., Viers, J., and Dupré, B., 2014, Trace elements in river waters , in Mackenzie, F., editor, Sediments, Diagenesis, and Sedimentary Rocks: Treatise on Geochemistry, Second Edition, v. 7, p. 195-235, https://doi.org/10.1016/B978-0-08-095975-7.00507-6

Golla, J. K., Kuessner, M. L., Henehan, M. J., Bouchez, J., Rempe, D. M., and Druhan, J. L., 2021, The evolution of lithium isotope signatures in fluids draining actively weathering hillslopes: Earth and Planetary Science Letters, v. 567, p. 116988, https://doi.org/10.1016/j.epsl.2021.116988

Guelke, M., and von Blanckenburg, F., 2007, Fractionation of stable iron isotopes in higher plants: Environmental Science and Technology, v. 41, n. 6, p. 1896-1901, https://doi.org/10.1021/es062288j

Guibourdenche, L., Stevenson, R., Pedneault, K., Poirier, A., and Widory, D., 2020, Characterizing nutrient pathways in Québec (Canada) vineyards: Insight from stable and radiogenic strontium isotopes: Chemical Geology, v. 532, p. 119375, https://doi.org/10.1016/j.chemgeo.2019.119375 
Gupta, D. K., Deb., U., Walther, C., and Chatterjee, S., 2018, Strontium in the ecosystem: Transfer in plants via root system , in Gupta, D. K., and Walter, C., editors, Behavior of strontium in plants and the environment: Cham, Springer, p. 1-18, https://doi.org/10.1007/978-3-319-66574-0_1

Hajj, F., Poszwa, A., Bouchez, J., and Guérold, F., 2017, Radiogenic and "stable" strontium isotopes in provenance studies: A review and first results on archaeological wood from shipwrecks: Journal of Archaelogical Science, v. 86, p. 24-49, https://doi.org/10.1016/j.jas.2017.09.005

Hanger, B. C., 1979, The movement of calcium in plants: Communications in Soil Sciences and Plant Anals, v. 10, n. 1-2, p. 171-193, https://doi.org/10.1080/00103627909366887

Hättenschwiler, S., Coq, S., Barantal, S., and Handa, I. T., 2011, Leaf traits and decomposition in tropical rainforests: Revisiting some commonly held views and towards a new hypothesis: New Phytologist, v. 189, n. 4, p. 950-965, https://doi.org/10.1111/j.1469-8137.2010.03483.x

Hewawasam, T., von Blanckenburg, F., Schaller, M., and Kubik, P. W., 2003, Increase of human over natural erosion rates in tropical highlands constrained by cosmogenic nuclides: Geology, v. 31, n. 7, p. $597-$ 600, https:/ / doi.org/10.1130/0091-7613(2003)031<0597:IOHONE >2.0.CO;2

Hewawasam, T., von Blanckenburg, F., Bouchez, J., Dixon, J. L., Schuessler, J. A., and Maekeler, R., 2013 Slow advance of the weathering front during deep, supply-limited saprolite formation in the tropical Highlands of Sri Lanka: Geochimica et Cosmochimica Acta, v. 118, p. 202-230, https://doi.org/10 $.1016 /$ j.gca.2013.05.006

Horwitz, E. P., Chiarizia, R., and Dietz, M. L., 1992, A novel strontium-selective extraction chromatographic resin: Solvent Extraction and Ion Exchange, v. 10, n. 2, p. 313-336, https://doi.org/10.1080/ 07366299208918107

Jacobson, A. D., Blum, J. D., Chamberlain, C. P., Poage., M. A., and Sloan, V. F., 2002, Ca/Sr and Sr isotope systematics of a Himalayan glacial chronosequence: Carbonate versus silicate weathering rates as a function of landscape surface age: Geochimica et Cosmochimica Acta, v. 66, p. 13-27, https://doi .org/10.1016/S0016-7037(01)00755-4

Kennedy, M. J., Chadwick, O. A., Vitousek, P. M., Derry, L. A., and Hendricks, D. M., 1998, Changing sources of base cations during ecosystem development, Hawaiian Islands: Geology, v. 26, n. 11, p. 1015 1018, https://doi.org/10.1130/0091-7613(1998)026<1015:CSOBCD >2.3.CO;2

Krabbenhöft, A., Fietzke, J., Eisenhauer, A., Liebetrau, V., Böhm, F., and Vollstaedt, H., 2009, Determination of radiogenic and stable strontium isotope ratios $\left({ }^{87} \mathrm{Sr} /{ }^{86} \mathrm{Sr}, \delta^{88 / 86} \mathrm{Sr}\right)$ by thermal ionization mass spectrometry applying an ${ }^{87} \mathrm{Sr} /{ }^{84} \mathrm{Sr}$ double-spike: Journal of Analytical Atomic Spectrometry, v. 24, p. 1267-1271, https://doi.org/10.1039/b906292k

Krabbenhöft, A., Eisenhauer, A., Böhm, F., Vollstaedt, H., Fietzke, J., Liebetrau, V., Augustin, N., PeuckerEhrenbrink, B., Müler, M. N., Horn, C., Hansen, B. T., Nolte, N., and Wallmann, K., 2010, Constraining the marine strontium budget with natural strontium isotope fractionations $\left({ }^{87} \mathrm{Sr} /{ }^{86} \mathrm{Sr}\right.$, $\delta^{88 / 86} \mathrm{Sr}$ ) of carbonates, hydrothermal solutions and river water: Geochimica et Cosmochimica Acta, v. 74, n. 14, p. 4097-4109, https://doi.org/10.1016/j.gca.2010.04.009

Kramchaninov, A. Y., Chernyshev, I. V., and Shatagin, K. N., 2012, Isotope analysis of strontium by multi-collector inductively coupled plasma mass spectrometry: High-precision com- bined measurements of ${ }^{88} \mathrm{Sr} /{ }^{86} \mathrm{Sr}$ and ${ }^{87} \mathrm{Sr} /{ }^{86} \mathrm{Sr}$ isotope ratios: Journal of Analytical Chemistry, v. 67, p. 1084-1092, https://doi .org/10.1134/S1061934812140067

Kurtz, A. C., Derry, L. A., and Chadwick, O. A., 2001, Accretion of Asian dust to Hawaiian soils: Isotopic, elemental, and mineral mass balances: Geochimica et Cosmochimica Acta, v. 65, n. 12, p. 1971-1983, https://doi.org/10.1016/S0016-7037(01)00575-0

Li, S., Li, W., Beard, B. L., Raymo, M. E., Wang, X., Chen, Y., and Chen, J., 2019, K isotopes as a tracer for continental weathering and geological K cycling: Proceedings of the National Academy of Sciences of the United States of America, v. 166, n. 18, p. 8740-8745, https://doi.org/10.1073/pnas.1811282116

Liu, F.-J., Hunsaker, C., and Bales, R. C., 2013, Controls of streamflow generation in small catchments across the snow-rain transition in the Southern Sierra Nevada, California: Hydrologial Processes, v. 27, n. 14, p. 1959-1972, https://doi.org/10.1002/hyp.9304

Ma, J. L., Wei, G. J., Liu, Y., Ren, Z. Y., Xu, Y. G., and Yang, Y. H, 2013, Precise measurement of stable $\left(\delta^{88}\right)$ $\left.{ }^{86} \mathrm{Sr}\right)$ and radiogenic $\left({ }^{87} \mathrm{Sr} /{ }^{86} \mathrm{Sr}\right)$ strontium isotope ratios in geological standard reference materials using MC-ICP-MS: Chinese Science Bulletin, v. 58, n. 25, p. 3111-3118, https://doi.org/10.1007/ s11434-013-5803-5

Maguire, M. E., and Cowan, J. A., 2002, Magnesium chemistry and biochemistry: BioMetals, v. 15, p. 203210, https://doi.org/10.1023/A:1016058229972

Misra, S., and Froelich, P. N., 2012, Lithium isotope history of Cenozoic seawater: Changes in silicate weathering and reverse weathering: Science, v. 335, n. 6070, p. 818-821, https://doi.org/10.1126/science .1214697

Moynier, F., Agranier, A., Hezel, D. C., and Bouvier, A., 2012, Sr stable isotope composition of Earth, the Moon, Mars, Vesta and meteorites: Earth and Planetary Science Letters, v. 300, n. 3-4, p. 359-366, https://doi.org/10.1016/j.epsl.2010.10.017

Neymark, L. A., Proemo, W. R., Mel'nikov, N. N., and Emsbo, P., 2014, Precise determination of $\delta^{88} \mathrm{Sr}$ in rocks, minerals, and waters by double-spike TIMS: A powerful too in the study of geological, hydrological and biological processes: Journal of Analytical and Atomic Spectromery, v. 29, n. 1, p. 65-75, https://doi.org/10.1039/C3JA50310K

Nezat, C. A., Blum, J. D., and Driscoll, C. T., 2010, Patterns of $\mathrm{Ca} / \mathrm{Sr}$ and ${ }^{87} \mathrm{Sr} /{ }^{86} \mathrm{Sr}$ variation before and after a whole watershed $\mathrm{CaSiO}_{3}$ addition at the Hubbard Brook Experimental Forest, USA: Geochimica et Cosmochimica Acta, v. 74, n. 11, p. 3129-3142, https://doi.org/10.1016/j.gca.2010.03.013

Norton, K. P., and von Blanckenburg, F., 2010 Silicate weathering of soil-mantled slopes in an active Alpine landscape: Geochimica et Cosmochimica Acta, v. 74, n. 18, p. 5243-5258, https://doi.org/10.1016/j .gca.2010.06.019 
Norton, K. P., von Blanckenburg, F., and Kubik, P. W., 2010, Cosmogenic nuclide-derived rates of diffusive and episodic erosion in the glacially sculpted upper Rhone Valley, Swiss Alps. Earth Surface Processes and Landforms, v. 35, n. 6, p. 651-662, https://doi.org/10.1002/esp.1961

Oeser, R. A., and von Blanckenburg, F., 2020a, Strontium isotopes trace biological activity in the Critical Zone along a climate and vegetation gradient: Chemical Geology, v. 558, p. 119861, https://doi.org/ 10.1016/j.chemgeo.2020.119861

Oeser, R. A., and von Blanckenburg, F., 2020b, Do degree and rate of silicate weathering depend on plant productivity?: Biogeosciences, v. 17, n. 19, p. 4883-4817, https://doi.org/10.5194/bg-17-4883-2020

Ohno, T., and Hirata, T., 2007, Simultaneous determination of mass-dependent isotopic fractionation and radiogenic isotope variation of strontium in geochemical samples by multiple collector-ICP-mass spectrometry: Analytical Sciences, v. 23, n. 11, p. 1275-1280, https://doi.org/10.2116/analsci.23.1275

Ohno, T., Komiya, T., Ueno, Y., Hirata, T., and Maruyama, S., 2008, Determination of ${ }^{88} \mathrm{Sr} /{ }^{86} \mathrm{Sr}$ mass-dependent isotopic fractionation and radiogenic isotope variation of ${ }^{87} \mathrm{Sr} /{ }^{86} \mathrm{Sr}$ in the Neoproterozoic Doushantuo Formation: Gondwana Research, v. 14, n. 1-2, p. 126-133, https://doi.org/10.1016/j.gr .2007.10.007

Pearce, C. R., Parkinson, I. J., Gaillardet, J., Chetelat, B., and Burton, K. W., 2015a, Characterizing the stable $\left(\delta^{88 / 86} \mathrm{Sr}\right)$ and radiogenic $\left({ }^{87} \mathrm{Sr} /{ }^{86} \mathrm{Sr}\right)$ isotopic composition of strontium in rainwater: Chemical Geology, v. 409, p. 54-60, https://doi.org/10.1016/j.chemgeo.2015.05.010

Pearce, C. R., Parkinson, I. J., Gaillardet, J., Charlier, B. L. A., Mokadem, F., and Burton, K. W., 2015b, Reassessing the stable $\left(\delta^{88 / 86} \mathrm{Sr}\right)$ and radiogenic $\left({ }^{87} \mathrm{Sr} /{ }^{86} \mathrm{Sr}\right)$ strontium isotopic composition of marine inputs: Geochimica et Cosmochimica Acta, v. 157, p. 125-146, https://doi.org/10.1016/j.gca.2015.02 .029

Pett-Ridge, J., Derry, L. A., and Kurtz, A. C., 2009, Sr isotopes as a tracer of weathering processes and dust inputs in a tropical granitoid watershed, Luquillo Mountains, Puerto Rico: Geochimica et Cosmochimica Acta, v. 73, n. 1, p. 25-43, https://doi.org/10.1016/j.gca.2008.09.032

Pin, C., and Bassin, C., 1992, Evaluation of a strontium-specific extraction chromatographic method for isotopic analysis in geological materials: Analytica Chimica Acta, v. 269, n. 2, p. 249-255, https://doi.org/ 10.1016/0003-2670(92) 85409-Y

Pokharel, R., Gerrits, R., Schuessler, J. A., Frings, P. J., Sobotka, R., Gorbushina, A. A., and von Blanckenburg, F., 2018, Magnesium stable isotope fractionation on a cellular level explored by cyanobacteria and black fungi with implications for higher plants: Environmental Science and Technology, v. 52, p. 12216-12224, https://doi.org/10.1021/acs.est.8b02238

Poszwa, A., Dambrine, E., Pollier, B., and Atteia, O., 2000, A comparison between Ca and Sr cycling in forest ecosystems: Plant and Soils, v. 225, p. 299-310.

Poszwa, A., Dambrine, É., Ferry, B., Pollier, B., and Loubet, M., 2002, Do deep tree roots provide nutrients to the tropical rainforest?: Biogeochemistry, v. 60, p. 97-18, https://doi.org/10.1023/A: 1016548113624

Quade, J., Chivas, A. R., and McCulloch, M. T., 1995, Strontium and carbon isotope tracers and the origins of soil carbonate in South Australia and Victoria: Palaeogeography, Palaeoclimatology, Palaeoecology, v. 113, n. 1, p. 103-117, https://doi.org/10.1016/0031-0182(95)00065-T

Raddatz, J., Liebetrau, V., Rüggeberg, A., Hathorne, E., Krabbenhöft, A., Eisenhauer, A., Böhm, F., Vollstaedt, H., Fietzke, J., López Correa, M., Freiwald, A., and Dullo, W.-C., 2013, Stable Sr-isotope, Sr/ $\mathrm{Ca}, \mathrm{Mg} / \mathrm{Ca}, \mathrm{Li} / \mathrm{Ca}$ and $\mathrm{Mg} / \mathrm{Li}$ ratios in the scleractinian cold-water coral Lophelia pertusa: Chemical Geology, v. 352, p. 143-152, https://doi.org/10.1016/j.chemgeo.2013.06.013

Rediske, J. H., and Selders, A. A., 1953, The absorption and translocation of strontium by plants. Plant Physiology, v. 28, n. 4, p. 594-605, https://doi.org/10.1104/pp.28.4.594

Romaniello, S. J., Field, M. P., Smith, H. B., Gordon, G. W., Kim, M. H., and Anbar, A. D,. 2015, Fully automated chromatographic purification of $\mathrm{Sr}$ and $\mathrm{Ca}$ for isotopic analysis: Journal of Analytical and Atomic Spectrometry, v. 30, n. 9, p. 1906-1912, https://doi.org/10.1039/C5JA00205B

Rüggeberg, A., Fietzke, J., Liebetrau, V., Eisenhauer, A., Dullo, W.-F., and Freiwald, A., 2008, Stable strontium isotopes $\left(\delta^{88 / 86} \mathrm{Sr}\right)$ in cold-water corals - A new proxy for reconstruction of intermediate ocean water temperature: Earth and Planetary Science Letters, v. 269, n. 3-4, p. 570-575, https:// doi.org/10.1016/j.epsl.2008.03.002

Scher, H. D., Griffith, E. M., and Buckley, W. B. Jr., 2014, Accuracy and precision of ${ }^{88} \mathrm{Sr} /{ }^{86} \mathrm{Sr}$ and ${ }^{87} \mathrm{Sr} /{ }^{86} \mathrm{Sr}$ measurements by MC-ICP-MS compromised by high barium concentrations: Geochemistry, Geophysics, Geosystems, v. 15, n. 2, GC005134, https://doi.org/10.1002/2013GC005134

Schmitt, A. D., Vigier, N., Lemarchand, D., Millot, R., Stille, P., and Chabaux, F., 2012, Processes controlling the stable isotope compositions of $\mathrm{Li}, \mathrm{B}, \mathrm{Mg}$ and $\mathrm{Ca}$ in plants, soils and waters: $\mathrm{A}$ review: Comptes Rendus Geoscience, v. 344, n. 11-12, p. 704-722, https://doi.org/10.1016/j.crte.2012.10.002

Schuessler, J. A., von Blanckenburg, F., Bouchez, J., Uhlig, D., and Hewawasam, T., 2018, Nutrient cycling in a tropical montane rainforest under a supply-limited weathering regime traced by elemental mass balances and $\mathrm{Mg}$ stable isotopes: Chemical Geology, v. 497, p. 74-87, https://doi.org/10.1016/j .chemgeo.2018.08.024

Shalev, N., Segal, I., Lazar, B., Gavrieli, I., Fietzke, J., Eisenhauer, A., and Halicz, L., 2013, Precise determination of $\delta^{88 / 86} \mathrm{Sr}$ in natural samples by double-spike MC-ICP-MS and its TIMS verification: Journal of Analytical Atomic Spectrometry, v. 28, p. 940-944, https://doi.org/10.1039/c3ja50039j

Shalev, N., Gavrieli, I., Halicz, L., Sandler, A., Stein, M., and Lazar, B., 2017, Enrichment of ${ }^{88} \mathrm{Sr}$ in continental waters due to calcium carbonate precipitation: Earth and Planetary Science Letters, v. 459, p. 381-393, https://doi.org/10.1016/j.epsl.2016.11.042

Stevenson, E. I., Hermoso, M., Rickaby, R. E. M., Tyler, J. J., Minoletti, F., Parkinson, I. J., Mokadem, F., and Burton, K. W., 2014, Controls on stable strontium isotope fractionation in coccolithophores with 
implications for the marine Sr cycle: Geochimica et Cosmochimica Acta, v. 128, p. 225-235, https:// doi.org/10.1016/j.gca.2013.11.043

Stevenson, E. I., Aciego, S. M., Chutcharavan, P., Parkison, I. J., Burton, K. W., Blakowski, M. A., and Arendt, C. A., 2016, Insight into combined radiogenic and stable stontium isotopes as tracers for weathering processes in subglacial environments: Chemical Geology, v. 429, p. 33-43, https://doi.org/10 $.1016 / \mathrm{j}$. chemgeo.2016.03.008

Stevenson, R., Pearce, C. R., Rosa, E., Hélie, J.-F., and Hillaire-Marcel, C., 2018, Weathering processes, catchment geology and river management impacts on radiogenic $\left({ }^{87} \mathrm{Sr} /{ }^{86} \mathrm{Sr}\right)$ and stable $\left(\delta^{88 / 86} \mathrm{Sr}\right)$ strontium isotope compositions of Canadian boreal rivers: Chemical Geology, v. 486, p. 50-60, https://doi.org/10.1016/j.chemgeo.2018.03.039

Sullivan, P. L., Ma, L., West, N., Jin, L., Karwan, D. L., Noireaux, J., Steinhoefel, G., Gaines, K. P., Eissenstat, D. M., Gaillardet, J., Derry, L. A., Meek, K., Hynek, S., and Brantley, S. L., 2016, CZ-tope at Susquehanna Shale Hills CZO: Synthesizing multiple isotope proxies to elucidate Critical Zone processes across timescales in a temperate forested landscape: Chemical Geology, v. 445, p. 103-119, https://doi.org/10.1016/j.chemgeo.2016.05.012

Tessier, A., Campbell, P. G. C., and Bisson, M., 1979, Sequential extraction procedure for the speciation of particulate trace metals: Analytical Chemistry, v. 51, n. 7, p. 844-851, https://doi.org/10.1021/ ac50043a017

Trostle, K. D., Runyon, J. R., Pohlmann, M. A., Redfield, S. E., Pelletier, J., McIntosh, J., and Chorover, J., 2017, Colloids and organic matter complexation control trace metal concentration-discharge relationships in Marshall Gulch stream waters: Water Resources Research, v. 52, n. 10, p. 7931-7944, https:// doi.org/10.1002/2016WR019072

Uhlig, D., and von Blanckenburg, F., 2019, How slow rock weathering balances nutrient loss during fast forest floor turnover in montane, temperate forest ecosystems: Frontiers in Earth Sciences, v. 7, p. 159, https://doi.org/10.3389/feart.2019.00159

Uhlig, D., Schuessler, J. A., Bouchez, J., Dixon, J. L., and von Blanckenburg, F., 2017, Quantifying nutrient uptake as driver of rock weathering in forest ecosystems by magnesium stable isotopes: Biogeosciences, v. 14, p. 3111-3128, https://doi.org/10.5194/bg-14-3111-2017

Uhlig, D., Amelung, W., and von Blanckenburg, F., 2020, Mineral nutrients sourced in deep regolith sustain long-term nutrition of mountainous temperate forests ecosystems: Global Biogeochemical Cycles, v. 34, n. 9, https://doi.org/10.1029/2019GB006513

Vitousek, P. M., Kennedy, M. J., Derry, L. A., and Chadwick, O. A, 1999, Weathering versus atmospheric sources of strontium in ecosystems on young volcanic soils: Oecologia, v. 121, p. 255-259, https://doi . org $/ 10.1007 / \mathrm{s} 004420050927$

Vollstaedt, H., Eisenhauer, A., Wallmann, K., Böhm, F., Fietzke, J., Liebetrau, V., Krabbenhöft, A., Farkas, J., Tomasovych, A., Raddatz, J., and Veizer, J., 2014, The Phanerozoic $\delta^{88 / 86}$ Sr record of seawater: New constraints on past changes in oceanic carbonate fluxes: Geochimica Cosmochimica Acta, v. 128, p. 249-265, https://doi.org/10.1016/j.gca.2013.10.006

von Blanckenburg, F., Hewawasam, T., and Kubik, P. W., 2004, Cosmogenic nuclide evidence for low weathering and denudation in the wet, tropical highlands of Sri Lanka: Journal of Geophysical ResearchEarth Surface, v. 109, n. F3, p. F03008, https://doi.org/10.1029/2003JF000049

von Blanckenburg, F., von Wirén, N., Guelke, M., Weiss, D. J., and Bullen, T. D., 2009, Fractionation of Metal Stable Isotopes by Higher Plants: Elements, v. 5, n. 6, p. 375-380, https://doi.org/10.2113/ gselements.5.6.375

von Blanckenburg, F., Wittmann, H., and Schuessler, J. A., 2016, HELGES: Helmholtz Laboratory for the Geochemistry of the Earth Surface: Journal of large-scale research facilities, v. 2, https://doi.org/10 $.17815 /$ jlsrf-2-141

von Blanckenburg, F., Schuessler, J. A., Bouchez, J., Frings, P. J., Uhlig, D., Oelze, M., Frick, D. A., Hewawasam, T., Dixon, J., and Norton, K., 2021, Rock weathering and nutrient cycling along an erodosequence: American Journal of Science, v. 321, n. 8, p. 1111-1163, https://doi.org/10.2475/08.2021 .01

Wang, Q.-L., Chetelat, B., Zhao, Z.-Q., Ding, H., Li, S.-L., Wang, B.-L., Li, J., and Liu, X.-L., 2015, Behavior of lithium isotopes in the Changjiang River system: Sources effects and response to weathering and erosion: Geochimica et Cosmochimica Acta, v. 151, p. 117-132, https://doi.org/10.1016/j.gca.2014.12 .015

Wanner, C., Bucher, K., Pogge von Strandmann, P. A. E., Waber, H. N., and Pettke, T, 2017, On the use of $\mathrm{Li}$ isotopes as a proxy for water-rock interaction in fractured crystalline rocks: A case study from the Gotthard rail base tunnel: Geochimica et Cosmochimica Acta, v. 198, p. 396-418, https://doi.org/10 .1016/j.gca.2016.11.003

Wei, G. J., Ma, J. L., Liu, Y., Xie, L. H., Lu, W. J., Deng, W. F., Ren, Z. Y., Zeng, T., and Yang, Y. H., 2013, Seasonal changes in the radiogenic and stable strontium isotopic composition of Xijiang River water: Implications for chemical weathering: Chemical Geology, v. 343, p. 67-75, https://doi.org/10.1016/j .chemgeo.2013.02.004

West, A. J., Galy, A., and Bickle, M., 2005, Tectonic and climatic controls on silicate weathering: Earth and Planetary Science Letters, v. 235, n. 1-2, p. 211-228, https://doi.org/10.1016/j.epsl.2005.03.020

Widanamage, I. H., Schauble, E. A., Scher, H. D., and Griffith, E. M., 2014, Stable strontium isotope fractionation in synthetic barite: Geochimica et Cosmochimica Acta, v. 147, p. 58-75, https://doi.org/10 .1016/j.gca.2014.10.004

Widanamage, I. H., Griffith, E. M., Singer, D. M., Scher, H. D., Buckley, W. B. Jr., and Senko, J. M., 2015, Controls on stable Sr-isotope fractionation in continental barite: Chemical Geology, v. 411, p. 215-227, https://doi.org/10.1016/j.chemgeo.2015.07.011 
Wiederhold, J., 2015, Metal stable isotope signatures as tracers in environmental geochemistry: Environmental Science and Technology, v. 49, n. 5, p. 2606-2624, https://doi.org/10.1021/es504683e

Wittmann, H., von Blanckenburg, F., Bouchez, J., Dannhaus, N., Naumann, R., Christl, M., and Gaillardet, J., 2012, The dependence of meteoric ${ }^{10} \mathrm{Be}$ concentrations on particle size in Amazon River bed sediment and the extraction of reactive ${ }^{10} \mathrm{Be} /{ }^{9} \mathrm{Be}$ ratios, Chemical Geology, v. 318-319, p. 126-138, https://doi.org/10.1016/j.chemgeo.2012.04.031

Yang, L., Peter, C., Panne, U., and Sturgeon, R. E., 2008, Use of Zr for mass bias correction in strontium isotope ratio determinations using MC-ICP-MS: Journal of Analytical and Atomic Spectrometry, v. 23, p. 1269-1274, https://doi.org/10.1039/b803143f 